\title{
Grotesque Corporeality:
}

\section{Queering the Bulge in Gay Male Underwear}

\author{
by \\ Joshua Nathaniel Williams \\ BDes, Ryerson University, 2011 \\ BA, Northern Kentucky University, 2004 \\ A MRP presented to Ryerson University \\ in partial fulfillment of the \\ requirements for the degree of \\ Master of Arts \\ in the program of \\ Fashion \\ Toronto, Ontario, Canada, 2018 \\ (C) Joshua Nathaniel Williams, 2018
}




\section{AUTHOR'S DECLARATION FOR ELECTRONIC SUBMISSION OF A MRP}

I hereby declare that I am the sole author of this MRP. This is a true copy of the MRP, including any required final revisions.

I authorize Ryerson University to lend this MRP to other institutions or individuals for the purpose of scholarly research.

I further authorize Ryerson University to reproduce this MRP by photocopying or by other means, in total or in part, at the request of other institutions or individuals for the purpose of scholarly research.

I understand that my MRP may be made electronically available to the public. 


\begin{abstract}
This creative Major Research Project (MRP) uses a practice-led research method approach to investigate a correlation between the queer body and the grotesque. The research questions attempt to explore the way queer bodies are used to transgress and subvert both heteronormative and homonormative ideologies and masculinities using grotesque humour. This project also examines the relationship between fashion and the body to resist normative values and ideals. Artistic practices combine to create a volume of work consisting of collage, underwear garments, and photographs. These creative outputs are then analyzed and discussed with a focus on Mikhail Bakhtin's theories of the grotesque and carnivalesque, Gilles Deleuze's theory of the Body without Organs, and queer theory.
\end{abstract}

Keywords: grotesque, carnivalesque, Body without Organs, BwO, queer theory, humour, fashion design, underwear 


\section{Acknowledgements}

First and foremost, I would like to express my appreciation and gratitude to my supervisor Joseph Medaglia for his knowledge, guidance, and enduring patience throughout the duration of this research project. I would also like to thank my second reader Dr. Lu Ann Lafrenz for all of her encouragement. Finally, I would like to thank my friends, family, colleagues, and classmates for their love and support. Special acknowledgements to Anna Romanovska for always lending an ear and feeding me, Ho Yin Siu for the amazing photos, Eric Tong for assisting with his slick drafting skills, and Shelley Haines for all of the laughter and driving me around. 


\section{Table of Contents}

Page

Author's Declaration..................................................................................................................................

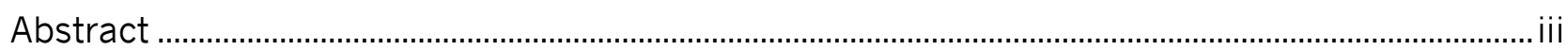

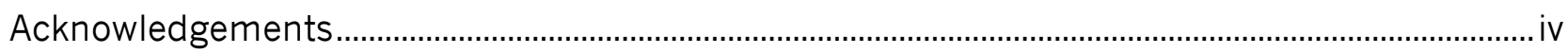

Table of Contents ....................................................................................................................................

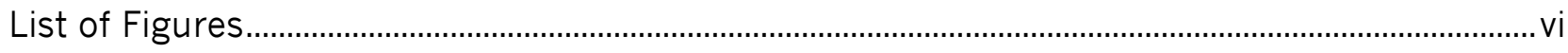

Chapter 1: Introduction \& Background …………………………………………………….....

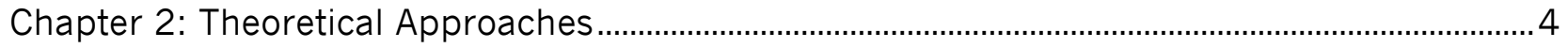

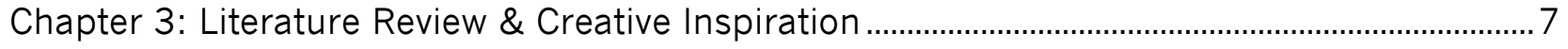

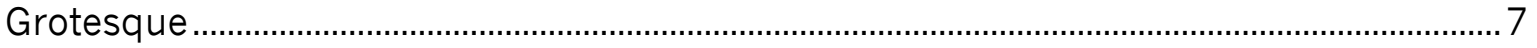

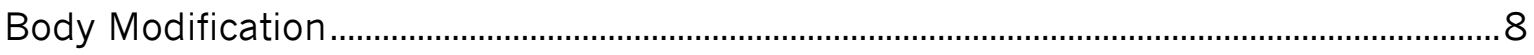

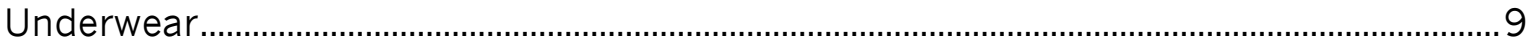

Art \& Performance

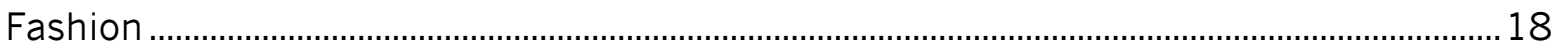

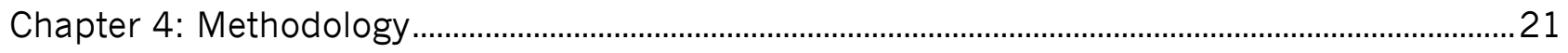

Chapter 5: Creative Method .................................................................................................................... 23

Concept Development...............................................................................................................

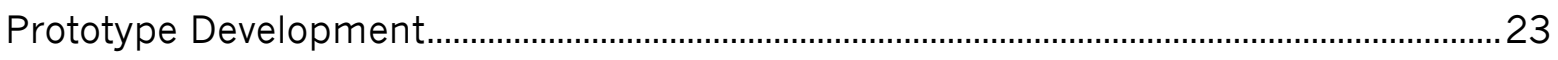

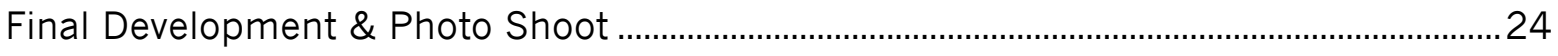

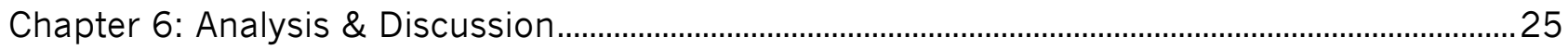

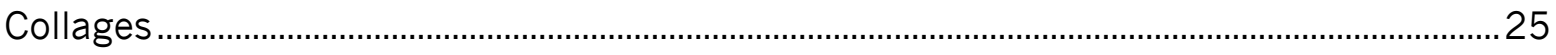

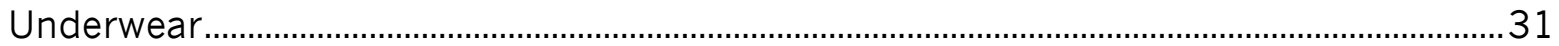

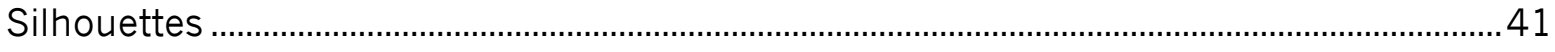

Chapter 7: Connections, Results, \& Future Development.....................................................................45

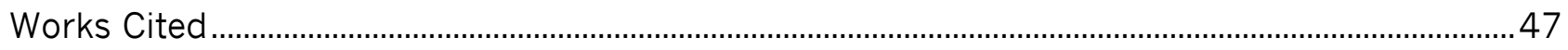




\section{List of Figures}

Page

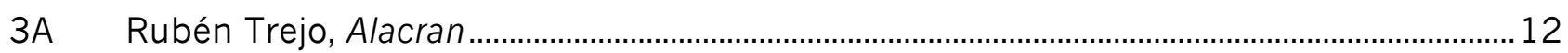

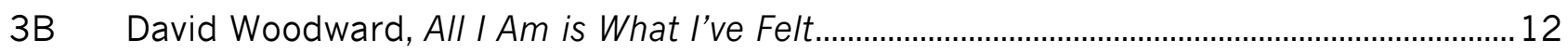

3C Philip Monk, Will Munro: History, Glamour, Magic ...................................................................13

3D Andrew Christian, "Almost Naked Dare Boxer, Yellow, X-Small”..........................................13

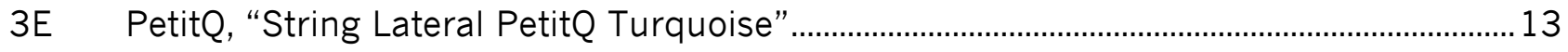

3F PetitQ, "Rift Bikini" .....................................................................................................................

3G Hillcrest Swimwear, "Magnum Shorts" .............................................................................. 14

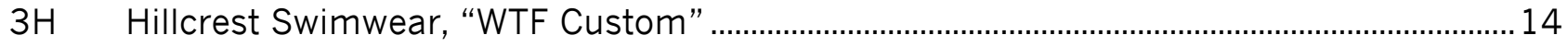

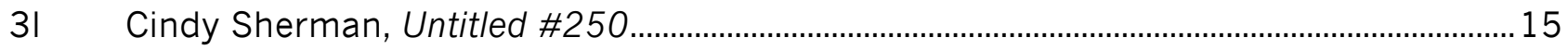

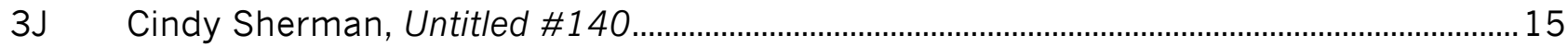

3K The Pavilion of Virginia Puff-Paint: An Artist Book by Jeremy Laing and Will Munro,

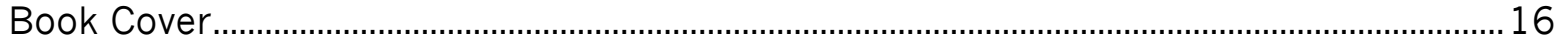

$3 \mathrm{~L} \quad$ Leigh Bowery and Nicola Bowery w/ Minty, 'The Birth' Performance ...................................16

3M Fergus Greer, Leigh Bowery / Session VI / Look 32 ………………………........................... 17

3N Fergus Greer, Leigh Bowery / Session II / Look 8 ................................................................17

30 Kishin Shinoyama, Body Meets Dress-Dress Meets Body ………………............................ 18

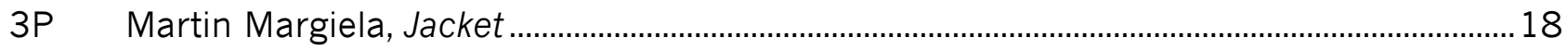

3Q Vetements x Levi's, "Vetements Men's Reworked Denim Jacket (Blue)"...........................20

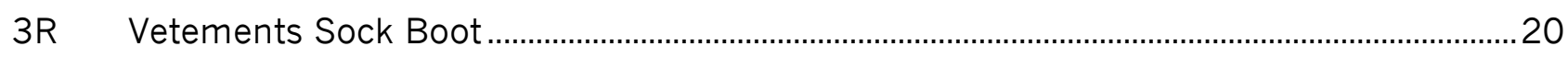

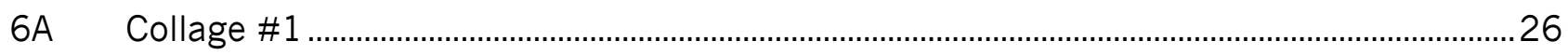

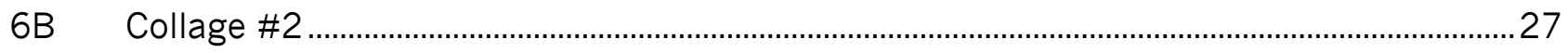

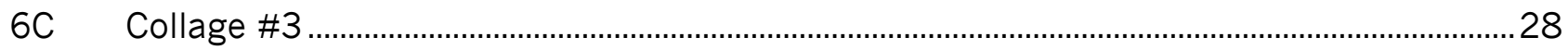

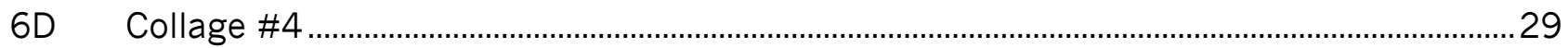

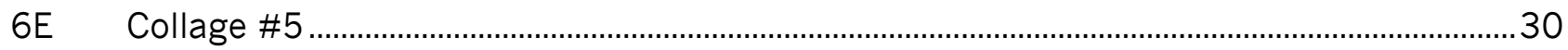

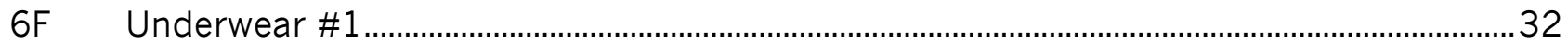

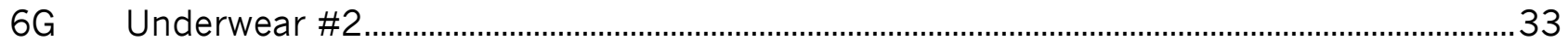

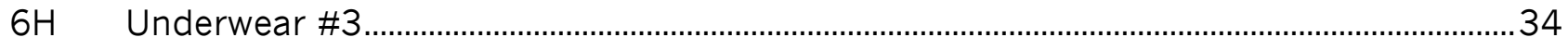

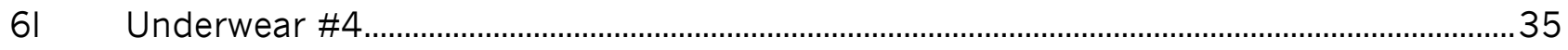

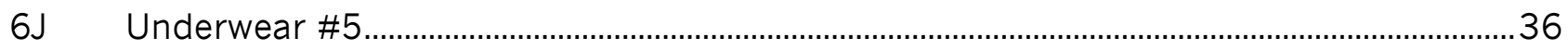

6K Silhouette Part 1 .................................................................................................................. 42

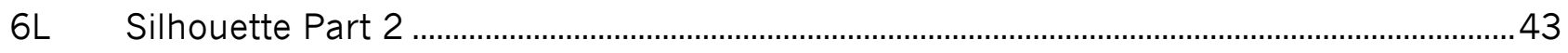

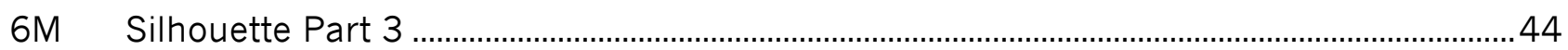




\section{Grotesque Corporeality:}

Queering the Bulge in Gay Male Underwear

\section{Introduction \& Background}

The purpose of this creative Major Research Project (MRP) is to explore an interconnection between queerness and the grotesque in relation to the body. Both queerness and grotesqueness exemplify the transgression of normative discourses and fundamentals; they both embody an otherness that operates outside of convention. In considering the body, which is the most outward presentation of self to society, this MRP focuses on fashion and garment design to produce a five-piece collection of underwear that aims to liberate the body and celebrate diversity and sexual nonconformity. In addition, artistic practices of collage and photography are used to further explore such interconnections. This MRP engages with Mikhail Bakhtin's ideas of the carnivalesque and the grotesque, Gilles Deleuze's theory of the Body without Organs, and queer theories that support the notion of identities, behaviours, and ways of knowing that operate outside of normative ideologies as posited by Judith Butler and Eve Kosofsky Sedgwick.

The term queer encompasses not only sexualities outside of heteronormative culture but also genders and identities that challenge and disrupt heteronormativity. This MRP embraces a concept of queer as grounded in acceptance, inclusivity, and intersectionality, which functions to provide a platform to resist oppressive normative culture and ideologies. In particular, this MRP aims to draw a link between queer and the grotesque with a focus on humour, exaggeration, and absurdity, mechanisms that are used to cope with otherness and difference. By engaging with such relationships, this MRP 
hopes to function as self-actuating pleasure and enjoyment in the face of oppression and the struggle for identity.

The outer limits of our physical bodies delineate our interactions with the known world. Therefore, this MRP focuses on queering the body through fashion and dress. In both queer and heteronormative communities, covering and adorning the body is a common practice that transcends sexual ideologies; i.e., sexual identity and dress exist independently and one does not directly determine the other. However, this MRP aims to demonstrate differences in body presentation between queer and normative ideologies, while simultaneously exploring creative processes and artifacts to arrive at new knowledge and ideas. The research questions this MRP engages with are as follows:

- How do we use our bodies as a site of grotesque humour to transgress heteronormative ideologies and illuminate deficiencies in the status quo?

- Simultaneously, how does the grotesque body subvert homonormative masculinities in establishing a queer identity?

- What role does fashion and its relationship to the body play in the transgression and resistance of normative values and ideals?

These inquiries present an opportunity for creative exploration, simultaneously providing the possibility to comprehend a subjective sexual identity marked by difference. To provide a lens in an attempt for hegemonic majorities to comprehend otherness, while adding to the growing body of work that defines queerness existing outside of normativity, a discussion of difference concentrating on the adornment and presentation of the physical body is emphasized. This discussion engages with the final output of the MRP's creative component, highlighting the importance of making queer art, while blurring the 
boundary between art and fashion in an attempt to break conventions and liberate the body from oppressive ideologies.

To situate my own reflexivity within the discourse of this MRP, I am focusing on a queer cis-gendered male perspective in an attempt to explore how men in general, and gay-identifying men in particular, self-actualize their physical identity through their choices in underwear. Viewing underwear's potential to display identity and self-presentation, I focus primarily on the contouring of the body through the manipulation of the male genital bulge (hereafter simply referred to as the bulge). I seek to confront modes of both hetero- and homonormative masculinities that media and culture prescribe as physical ideals, and attempt to confront these modes through the establishment of alternative appearances of bulging grotesquerie. Finally, this MRP aims to illuminate relationships between two non-visible features (aspects usually unseen or expressed in public); sexual identity and self-presentation through underwear. 


\section{Theoretical Approaches}

To assist with the creative output for this MRP, I primarily relied on the Deleuzian theory of the Body without Organs (BwO) and Bakhtinian theories of the grotesque and carnivalesque. These theories propelled the creation of underwear, and upon completion, helped to inform the creative analysis of the underwear.

In order to understand the $\mathrm{BwO}$, it is important to highlight the concept of becoming that underpins most of Deleuze's philosophy of life. The Oxford English Dictionary defines the philosophical concept of 'becoming' as "A coming to be, a passing into a state." Gilles Deleuze and Félix Guattari argue that becomings can only be understood as minoritarian in nature. They explain of a dichotomy between minoritarian and majoritarian, wherein the majority of man, presumably adult white [heterosexual] male, presupposes a natural hegemony over all other lifeforms in the universe (Thousand 291). This concept of becoming (minoritarian) that underlies a majority of Deleuze and Guattari's work can be explained as "a practice of change and of 'repetitions with a difference'," which is inherent to the evolution of human identity throughout one's lifetime as opposed to static monotony (Smelik 167). This is bolstered by the statement "Becoming is a rhizome, not a classificatory or genealogical tree" (Deleuze and Guattari, Thousand 239). Building on this concept of change is the idea of the Body without Organs, the main objective being "to undo the organization of the embodied 'self' as a fixed form of identity" (Smelik 172). Modeled from the musings of French playwright Antonin Artaud, Deleuze and Guattari present the BwO as a vessel devoid of organization that struggles to break free from judgement and stratification imposed by God/culture/society. Freedom from these restraints will consequently allow for creative experimentation (Thousand 14966). As Anneke Smelik suggests, since the essence of fashion can be regarded as a 
barometer of currency, its power can also be harnessed to "search for pockets of resistance" (180). Therefore, through the use of fashion and apparel, in this case underwear, this MRP aims to counter fixed identities and upset normativity through creative expression, and investigate the accumulating experiences and 'becomings' of sexual identity through fashion.

Mikhail M. Bakhtin developed his ideas of the grotesque and carnivalesque with his analysis and critique of François Rabelais's The Life of Gargantua and Pantagruel. In his study, Bakhtin proposes that the grotesque is an inversion of the familiar and a breach of boundaries that often disturbs, especially when involving the boundaries of the body (Granata, "Mikhail" 97). This creates a topsy-turvy world against normative realities that questions human existence. Comparable to the theories of Deleuze, Bahktin states:

The grotesque body ... is a body in the act of becoming. It is never finished, never completed; it is continually built, created, and builds and creates another body. Moreover, the body swallows the world and is itself swallowed by the world .... (Rabelais 317-318)

As Francesca Granata points out, focusing on Bakhtin's theories of the grotesque and carnivalesque is suitable for this MRP because of fashion's "inextricable relation to the body and norms of behaviour" ("Mikhail" 111), and norms are what this MRP seeks to subvert. As for the carnivalesque, Bakhtin explains carnival as a time when social hierarchies are suspended and there is free exchange between peoples regardless of oppressive and categorical factors (e.g. age, sex), and across all cultures independent of religious and class structural ideologies ("Carnival" 250-51). This notion of the 
carnivalesque is helpful to this MRP in order to celebrate difference and diversity, and to arrive at new knowledge that transgresses systematic limits.

To understand the body in terms of queerness, this MRP is supported by the writings of Judith Butler and Eve Kosofsky Sedgwick that define queer and assert its claim as difference in the face of heteronormativity. Using the categories of family and sexual identity as examples, Sedgwick defines queer as a misalignment of values within a socially constructed identity or space. This misalignment happens throughout one's life as the elements of construction ebb and flow to create a myriad of meanings and subjectivities that shift with time (Sedgwick 6-9). In essence, queer describes an "open mesh of possibilities" that deviates from normative ideologies (ibid. 8). Written prior to the emergence of queer theory, in "Performative Acts and Gender Constitution: An Essay in Phenomenology and Feminist Theory" Judith Butler claims historical forces naturalize gender identities through socially sanctioned performative repetition, and argues against gender as an intuitive characteristic tied to one's sex. Normalizing binary gender tropes, as well as hegemonic sexualities, ensures the survival of oppressive forces and institutions (519-28). By extension, the essence of queer is subversion and defiance of such naturalization. 


\section{Literature Review \& Creative Inspiration}

\section{Grotesque}

In order to undertake an MRP rooted in the grotesque, it is necessary to comprehend the origin and history of the grotesque. Related to the Italian word for cave, or grotto, the grotesque came into being as something that parallels the threatening darkness of the cave, while simultaneously compounded with a curious fascination of the

unknown. As a theoretical device, historically the grotesque often pertains to literary work. However, Frances S. Connelly has taken up theories of the grotesque as a common theme in her research and analysis of visual art. Especially notable is her focus on the grotesque in her book The Grotesque in Western Art and Culture: The Image at Play. In Connelly's study, she maintains that the grotesque is an action of play, and she identifies different strands of the grotesque that are useful in the analysis of artistic works. While these strands are distinct, they often overlap, and she organizes them into categories of improvisation, subversion, and trauma. All of these strands function to question modes of convention in some form or another. Specifically, the improvisational grotesque is aimed at literature and the arts, the subversive grotesque tests "social roles and [cultural] hierarchies," and the traumatic grotesque "threatens the limits of our identity, rupturing the boundaries between self and oblivion through the monstrous, the uncanny, or the abject (14).

In the book Grotesque for the New Critical Idiom series, Justin D. Edwards and Rune Graulund first interrogate the literary grotesque through the writings of John Ruskin, Mikhail Bakhtin, Michel Foucault, and Julia Kristeva. They then continue to analyze the cultural meanings of grotesque throughout history. Most helpful for this MRP is their 
explanation of grotesque bodies and body parts and their analysis of the relation between queerness and the grotesque. For Edwards and Graulund, grotesque bodies include natural deformities from birth, amalgamations of body parts like Mary Shelley's Frankenstein, parasitic and infectious mutations in the movies of David Cronenberg, and surgical composites as in Tom Six's film The Human Centipede (52). Investigating a link between queer and grotesque, they observe the paintings of Francis Bacon as his "ongoing articulation of the dynamics of representing the queer male body through the fragmentation, dissection and dissolution offered by the aesthetics of grotesquerie," while the novels of Dennis Cooper "include an aesthetics of ambiguity and ethical uncertainty that is revealed in grotesque representations of the queer body" (Edwards and Graulund 118).

This MRP utilizes the aforementioned readings about the grotesque to theoretically support its aims and promote its investigation. The remaining literature review and creative analysis includes an examination of a sampling of grotesquerie as it exists within the categories of body modification, underwear, art and performance, and fashion.

\section{Body Modification}

Presenting a body as grotesque, understanding ideas of queerness, and yet moving beyond an analysis of fashion leads to the culture of body modification as an act of grotesquerie. Types of body modification vary greatly, ranging from tattoos, piercings, implants, and cosmetic surgeries to scarification, dermal implants, and other extreme body modifications. Some prominent body modification practitioners include Pete Burns, Jocelyn Wildenstein, ORLAN, and Genesis P-Orridge. Body modifications share a direct link with the $\mathrm{BwO}$, since the severity of some modifications are a literal re-organization of the 
body as a foil to normative institutions and systems of power. On the one hand, body modification compares to Deleuze and Guattari's account of the masochist's BwO (Thousand 150-52), and on the other hand, it channels ideas of 'becoming.' Christian Klesse contends that "body modifications are deployed as visual signs of queer identification and sexual transgression [...]" (275). While these acts have been viewed as political and transgressive, scholars such as Annamari Vänskä directly link processes of body modification to the grotesque. Vänskä interprets a 'Classical body' as fixed, closed, and unchanging, while a 'grotesque body' is open; "the body of becoming and change, the body of unofficial culture" (156-58). Perceiving the body as a site of grotesque production informs this creative MRP and how it harnesses the different shapes and forms that the body may potentially employ.

In regards to the transmogrification of the body, and the bulge specifically, a direct correlation to this MRP is the sexual practice of scrotal saline infusion. As a case report substantiates, a man ordered a saline injection kit off of the Internet in order to enlarge his genitals, also known as "scrotal inflation" (Summers 716). However, this report only covers specifics from a medical perspective, and other studies on this procedure and the people who perform it are almost nonexistent. A search engine result leads to a site titled "Saline Infusion and You" for more information on the topic, and includes a link under the 'Resources' page to a product line of underwear made specifically for scrotal inflators and other well-endowed men, which is discussed in the following section.

\section{$\underline{\text { Underwear }}$}

The following articles and examples investigate the meaning of underwear and identity in a queer setting but do not attempt to present a visual connection between 
underwear, otherness, and grotesque inversion that questions normative ideologies. However, the following examples provide evidence of the historical existence of the relationship between gay and queer identities with underwear and the hegemonic suppression of the self-presentation through underwear. In addition, the following examples demonstrate visual artists that use underwear to explore genders and sexualities and the recognition of unconventional underwear markets.

Shaun Cole is a gay scholar who has written extensively on the topic of men's underwear. His book, The Story of Men's Underwear, examines underwear from a historical perspective, cataloguing medieval undergarments to the present. Cole's analysis includes style, fit, fabrication, branding, advertising, marketing, and consumption. Of greater relevance is Cole's study "Considerations on a Gentleman's Posterior" that investigates societal taboos regarding men's behinds, finding a correlation to insecurities surrounding homosexuality. He notes that "rear views in underwear advertisements are still far less common than front views, indicating, perhaps, that society is far more comfortable with a front view of a semi-naked man and his barely covered genitals than a view of his behind" ("Considerations" 218). The proliferation of front torso views and genital bulges in product advertising reinforces notions of ideal masculinities that this MRP seeks to subvert and an exploration of the posterior in underwear may generate creative output which further challenges the uncomfortableness that Cole's article suggests.

Several articles highlight how gay male desires have survived and even flourished amidst mainstream dominant culture. In the article "Skivvies with the Givvies: Vintage American Underwear Ads Feature Sexual Innuendo between "Boys" in the Brands," Bruce $\mathrm{H}$. Joffe uses vintage advertisements to investigate the plausibility of "homoerotic overtures, themes and subtexts within its messages" (6). Michele White's "Listing eBay 
Masculinity: Erotic Exchanges and Regulation in 'Gay' and 'Gay Interest' Underwear and Swimwear Auctions," illustrates the way that internet organizations regulate and normalize hegemonic assumptions of genders, masculinities, and sexualities. While Joffe's article serves to prove the enduring existence of "otherness" against heteronormative hegemony, White's article presents the reinforcement of normative ideologies in society that serve to marginalize unconventional identities. A focus of this MRP then seeks to resist marginalization by celebrating difference through a focus on gay male underwear.

Although underwear apparel is mostly hidden from daily public life, it is still an important shaper of identity and reflects a conscious choice in body presentation. José Blanco F. presents a personal narrative study of underwear in the article "Revealing Myself: A Phenomenological Approach to My Underwear Choices through the Years." Blanco F. reveals how underwear choice is undertaken as a process of appearance management, claiming that "underwear is important in the performance of our private and social identities and how it relates to masculinity, sexuality and other scripts of cultural convention" (129). A key finding of this article is how underwear garments lend to the construction of self-image and social-image, dependent on who this image is shared with (119).

Many visual artists have used underwear as a motif in their artwork. As a minority person of colour (American born of Mexican descent), Rubén Trejo once created a series of "calzones" (men's underwear) as commentary on the heteronormative concept of macho (Loste 454). Trejo used underwear and other everyday materials to create masks (see fig. 3A), which are highly symbolic in Latino cultures. Recently, David Woodward's fine arts thesis from Queen's University entitled "All I Am is What I've Felt" is a series of men's 


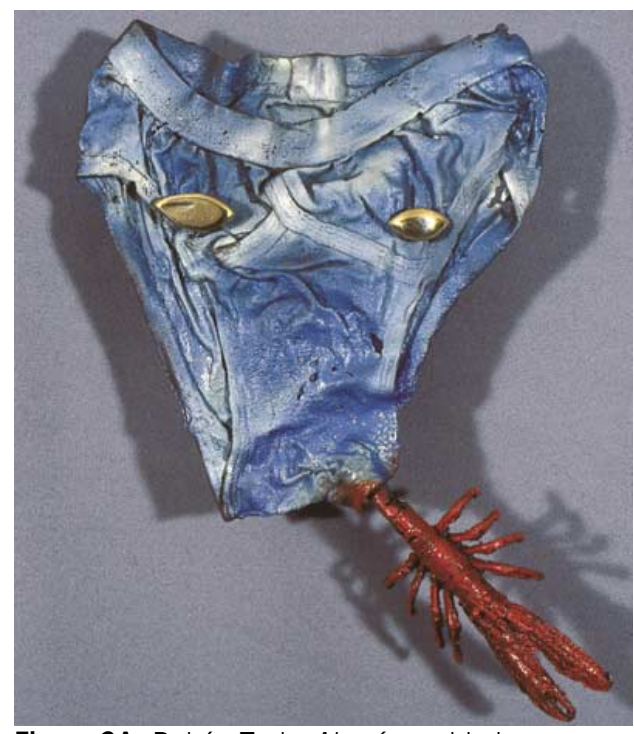

Figure 3A: Rubén Trejo, Alacrán, welded metal on cloth, 14" x 10", 1989.

Loste, Bárbara. "An Interview with Artist Rubén

Trejo." Latino Studies, vol. 1, no. 3, 2003.

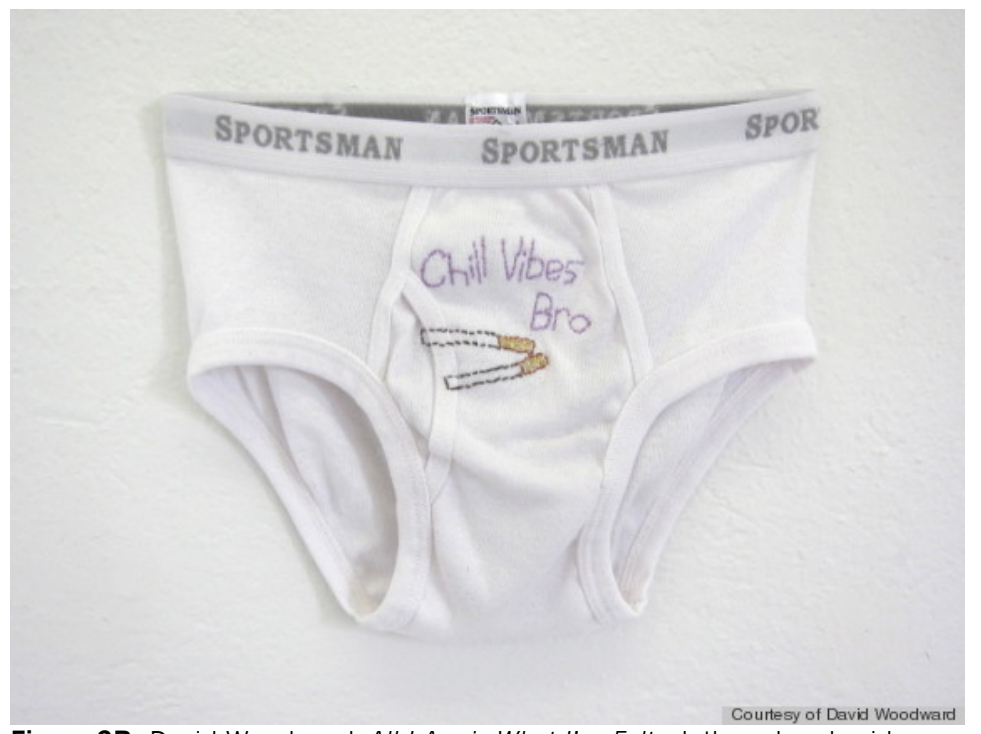

Figure 3B: David Woodward, All I Am is What I've Felt, cloth and embroidery thread, 2013.

https://www.huffingtonpost.ca/entry/underwear-art-display-davidwoodward_n_3391526

white briefs embroidered with images and text (see fig. 3B) that according to Woodward "is an examination of gender, sexuality and intimacy ..." (as qtd. in Hinkson). Using underwear quintessentially gendered male and encoded as masculine to comment on gender and sexuality is in effect queering a recognizable object, similar to this MRP's intent. Artist Will Munro often used underwear (see fig. 3C) in his projects to produce pieces such as "quilts, teddy bears and dollhouses. He has sewn political punk patches on Y-fronts and sliced up skivvies to create a skull logo for a black T-shirt" (Raphael). This article reveals that Munro's affinity for working with underwear came from a place of childhood and adolescent desires (Ibid.), which is a central feature of discourses on sexuality. Whereas Trejo's, Woodward's, and Munro's projects could classify as assemblage or deconstruction/reconstruction, the creation of underwear with unusual shapes to disguise and/or reveal have not been explored. This MRP can be viewed as an extension of other artists' work by distorting the fundamental nature of underwear as opposed to presenting underwear as a ready-made artefact. 


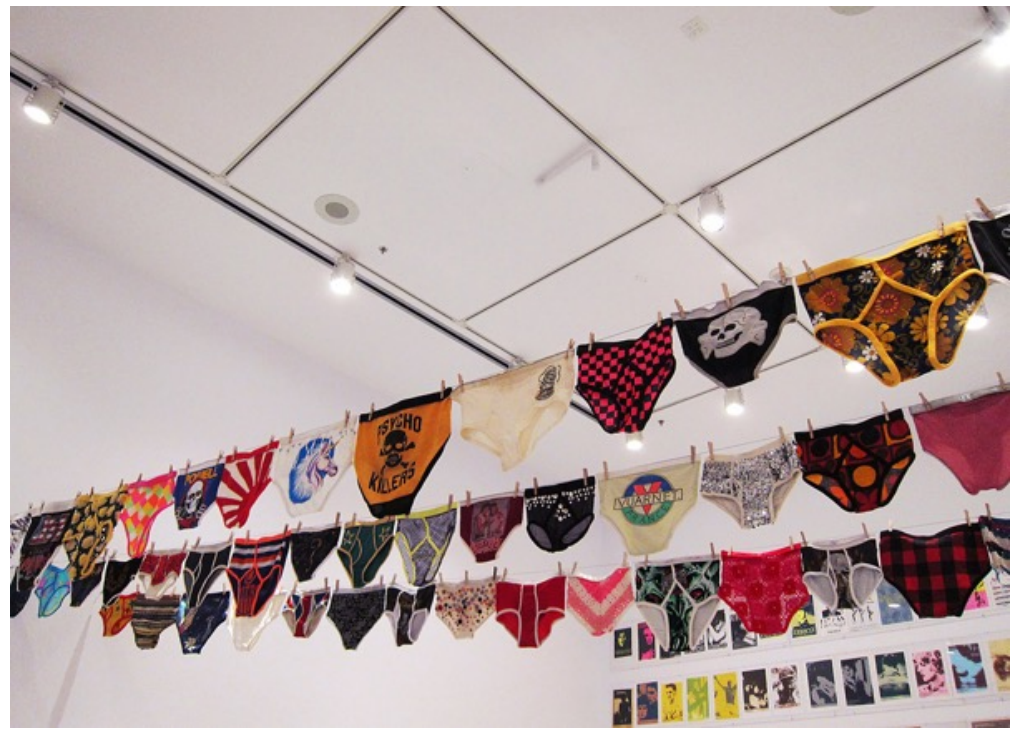

Figure 3C: Philip Monk, Will Munro: History, Glamour, Magic. Installation: Art Gallery of York University, 2012. Photo courtesy Jason Cawood. https://www.flickr.com/photos/jasoncawood/6910650437

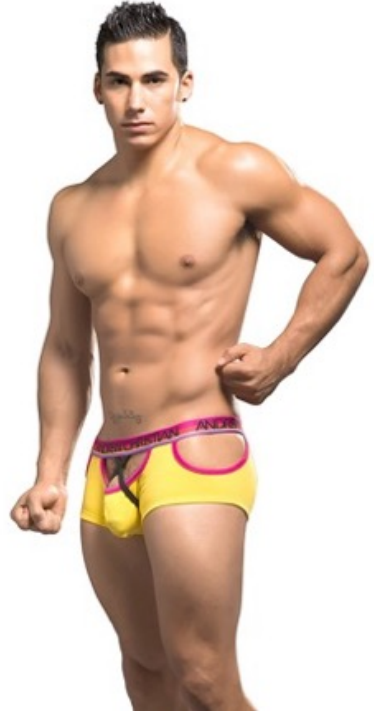

Figure 3D: Andrew Christian, "Almost Naked Dare Boxer, Yellow, X-Small."

https://www.amazon.co.uk/Almost-NakedBoxer-Yellow-X-Small/dp/B00WH385V4

The commercial side of underwear fashions for men reveals strong marketing toward gay males, often with a focus on the grotesque inversion of underwear's function and performance. Brands like Andrew Christian and PetitQ (see figs. 3D, 3E, 3F) disregard function in order to highlight bulges and body parts, often in an absurd display of

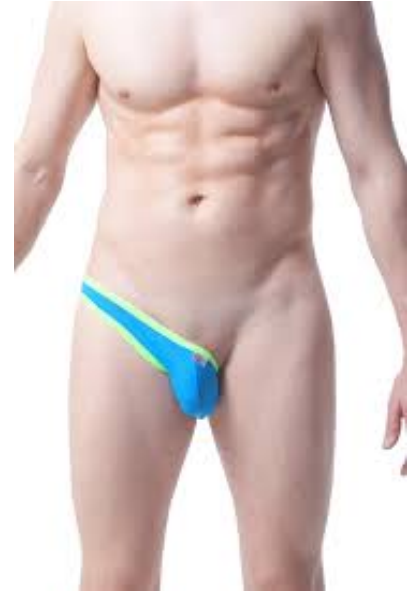

Figure 3E: PetitQ, "String Lateral PetitQ Turquoise."

https://www.amazon.fr/PetitQ-PQ8turq-String-Lateral-

Turquoise/dp/B0734L2N8Xh

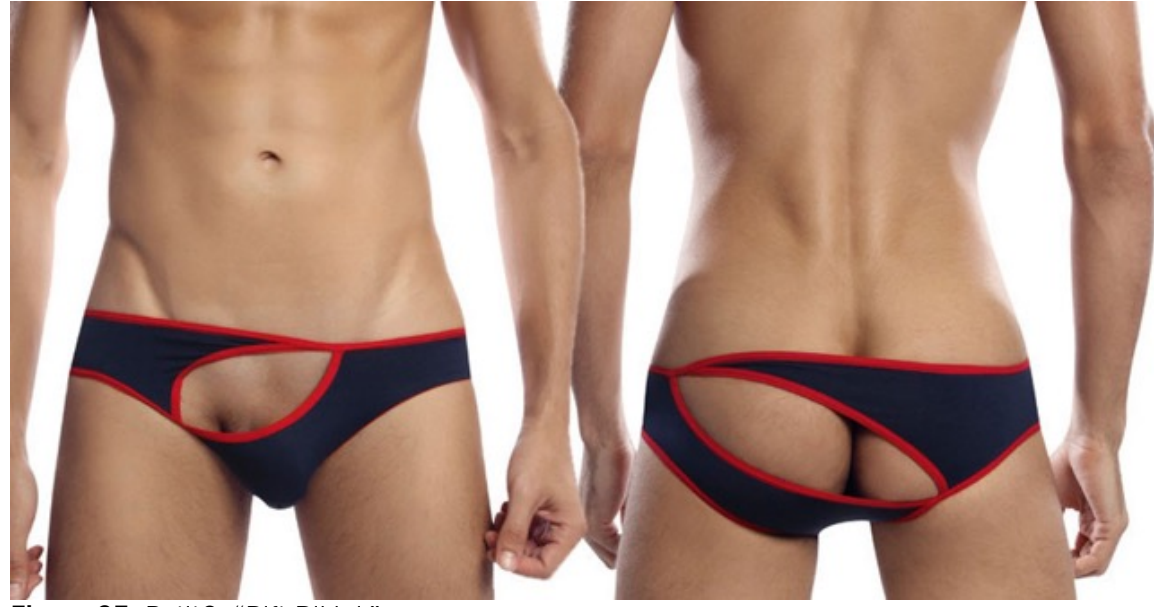

Figure 3F: PetitQ, "Rift Bikini."

https://www.underwearexpert.com/2016/03/new-underwear-petit-q/ 
incredulity. Mentioned previously under the discussion of body modification and scrotal inflation, Hillcrest Swimwear specializes in underwear and "Bulgewear" for "pumpers/injectors, ball stretchers and naturally endowed men throughout the world!" as stated on their website. The online shop features a wide array of available styles, a fabric gallery and style measurements, and a gallery of satisfied customers wearing the custom creations (see figs. 3G, 3H). This company demonstrates that target markets outside of hegemonic ones exist on the fringes of society, and also illustrates the grotesquerie of body modification (temporary scrotal inflation) and corresponding underwear fashion.

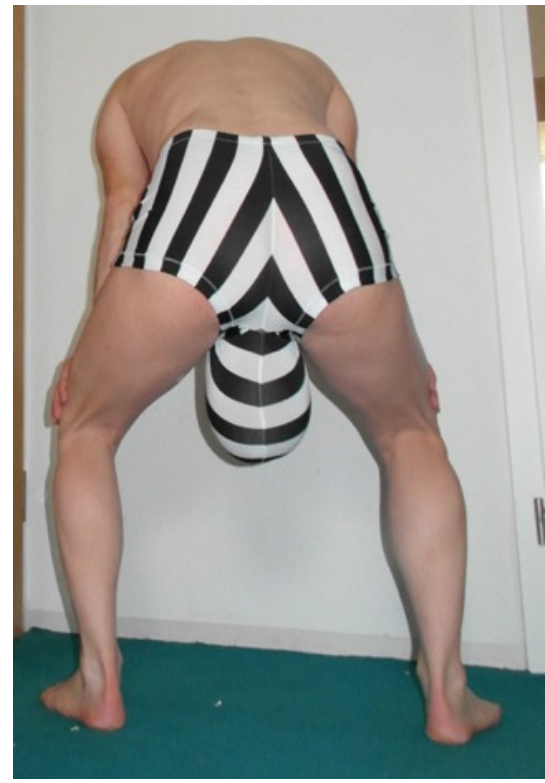

Figure 3G: Hillcrest Swimwear, "Magnum Shorts."

http://hillcrestswimwear.com/wp-

content/gallery/customer/jr44.jpg

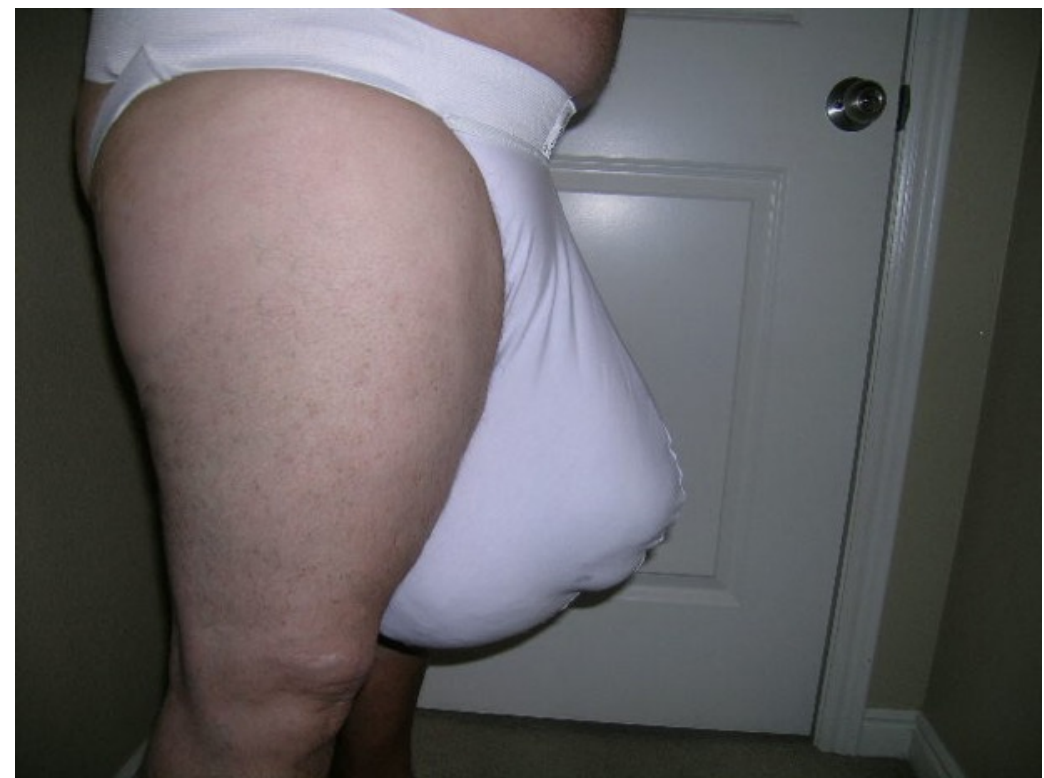

Figure 3H: Hillcrest Swimwear, "WTF Custom."

http://hillcrestswimwear.com/wp-content/gallery/customer/wtfwhite.jpg

\section{Art \& Performance}

In addition to contributions to academic study, this MRP extends from artists that deal with topics of the grotesque, sexuality, and the body. While Connelly's book The Grotesque in Western Art and Culture: The Image at Play is an excellent introduction to understanding the varieties of grotesque that exist in art from antiquity, it is important to 
analyze contemporary artists, working in mediums from photography to performance, to provide resonance to this MRP.

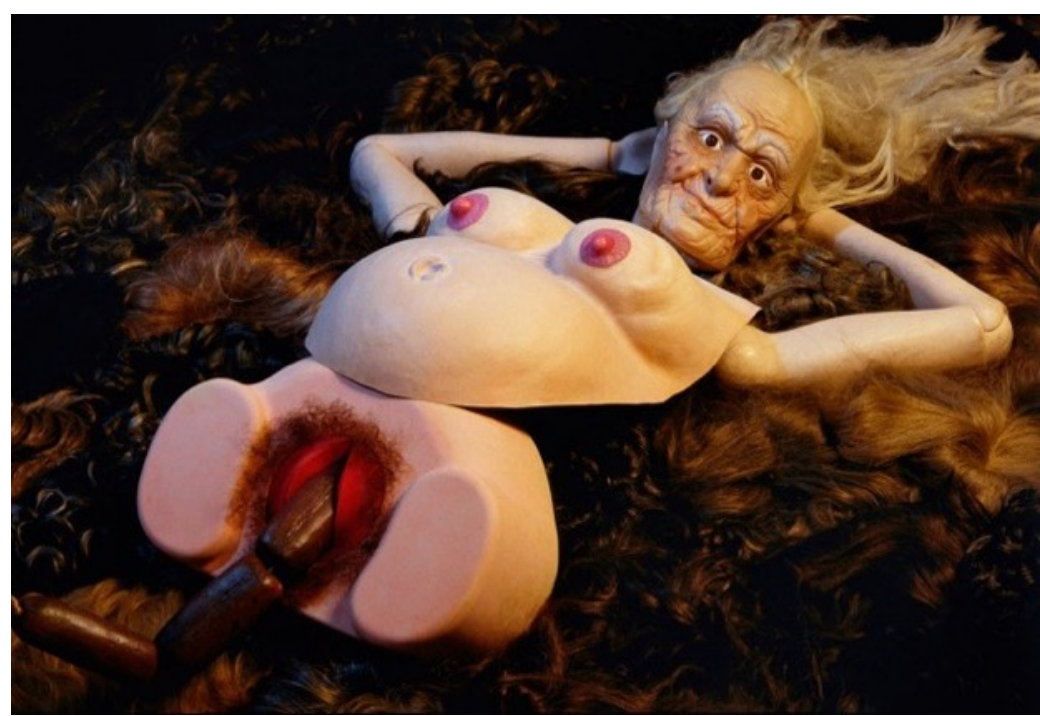

Figure 3I. Cindy Sherman, Untitled \#250, Chromogenic colour print, The Museum of Modern Art, 1992.

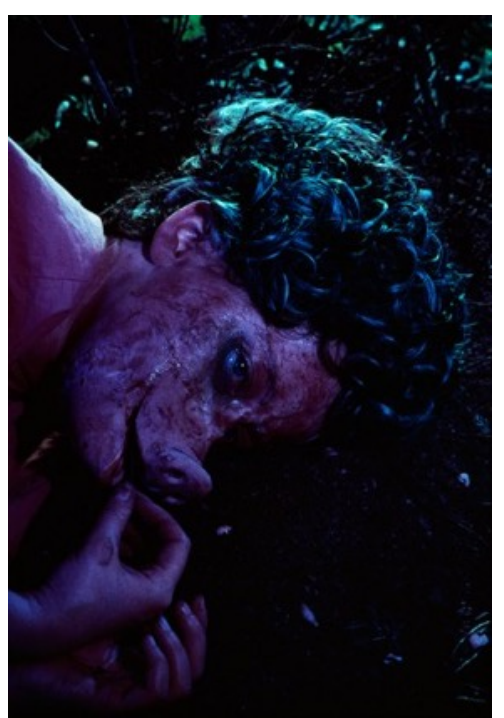

Figure 3J. Cindy Sherman, Untitled \#140, Chromogenic colour print, The Museum of Modern Art, 1985.

Handling such diverse themes as sex, fashion, dolls, prosthetics, violence, disaster, and masks, Cindy Sherman has created a vast body of work that underpins the various meanings of grotesquerie (see fig. 3I). Sherman's work continually pushes the boundaries of transgression, infusing the viewer with shock and discomfort with a curious appeal to witness her horrific transformations (see fig. 3J). From a feminist perspective, Laura Mulvey writes "She grotesquely parodies the kind of feminine image that is geared to erotic consumption, and she inverts conventional codes of female allure and elegance" (143). This MRP seeks to explore similar inversions of heteronormative convention through a queer lens, renouncing allure and elegance in favour of absurd and grotesque humour.

Known for his work with underwear, Will Munro teamed up with friend and fashion designer Jeremy Laing in 2004 to create an installation and performance piece titled the 
"Pavilion of Virginia Puff-Paint" (see fig. 3K). Writing for Canadian Art, R. M. Vaughan described the project as:

A high-concept exploration of the extensive, and extensively weird, subculture of textile-based sex fetishes ... the piece is a Victorian whorehouse run by Bonobo monkeys. Decorating a large tent with chintz, ornate furnishings, fluttering sheer curtains and themselves (costumed from head to toe in sequin-spattered, pink nylon bodysuits complete with multiple orifices and comically exaggerated sex organs), Laing and Munro, on video, proceed to screech and bellow like farm animals as they penetrate and re-penetrate each other in a beautifully choreographed display of polysexual perversity.

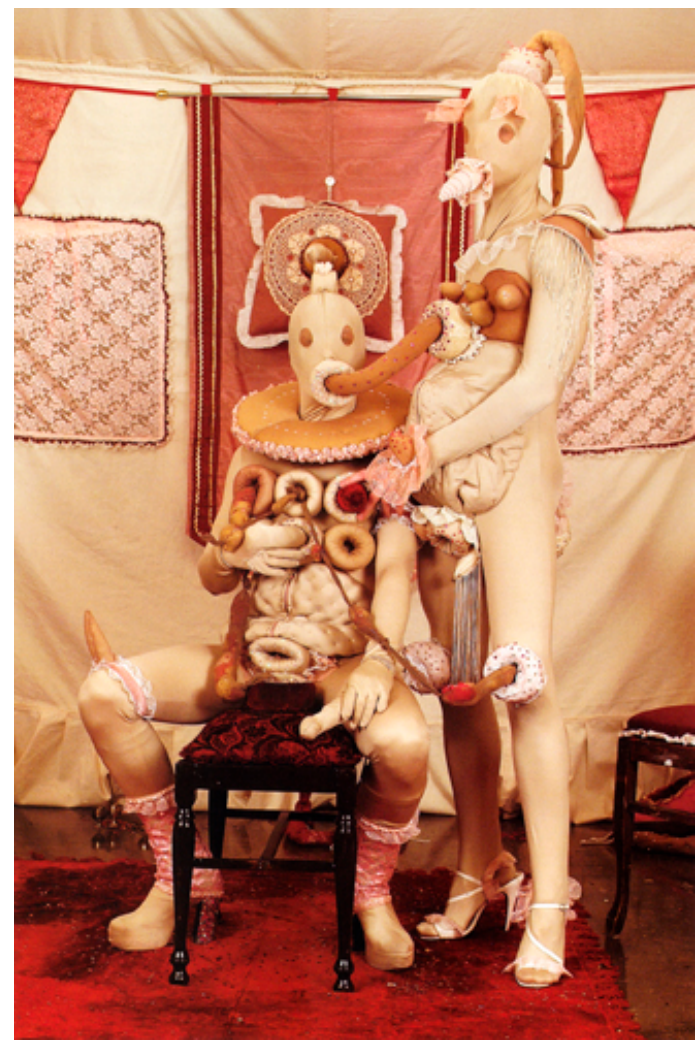

Figure 3K: The Pavilion of Virginia Puff-Paint: An Artist Book by Jeremy Laing and Will Munro, Book Cover, Art Gallery of York University, 2006.

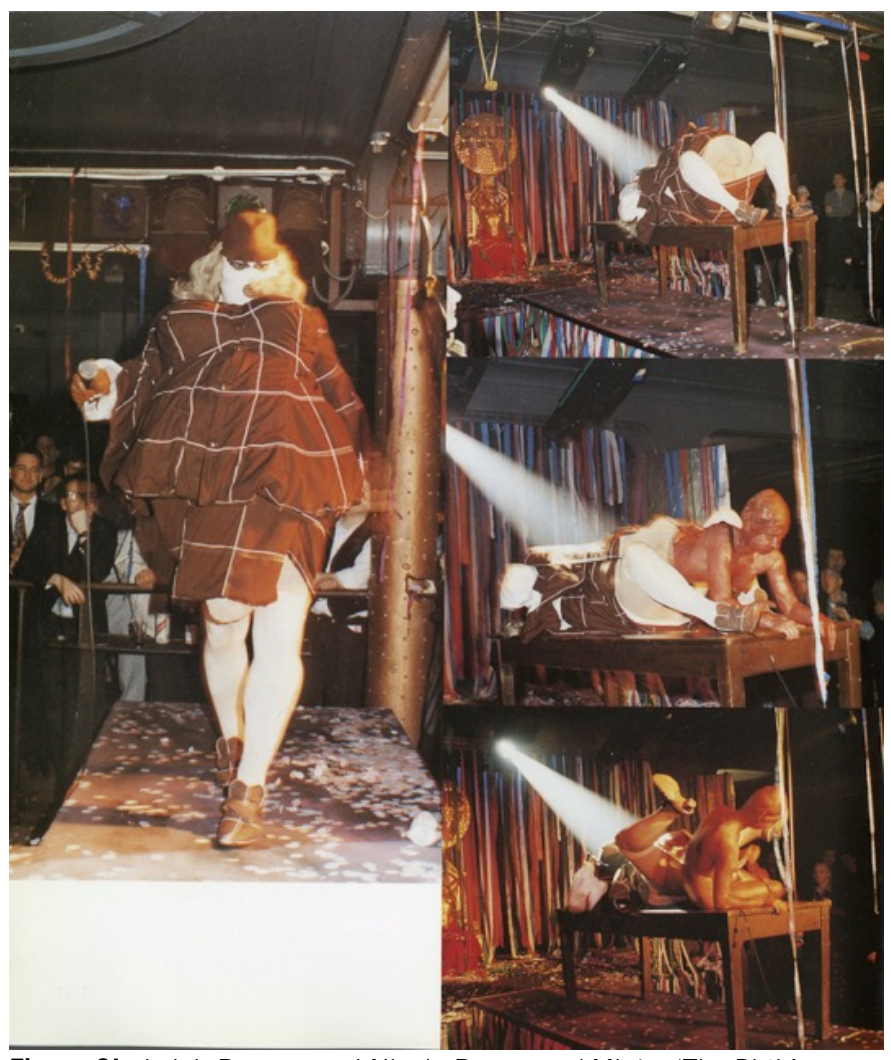

Figure 3L: Leigh Bowery and Nicola Bowery w/ Minty, 'The Birth' Performance, The Tunnel, Glasgow, 1993. Photos Courtesy Stewart Laing.

Leigh Bowery. Violette Editions, 1998. 
Here there exists a dichotomy between humour and disgust, causing the "dissolution of the borders separating the normal and abnormal, inside and outside, internal and external" (Edwards \& Graulund 9); the humorous aspect of such perversion is directly associated with the Rabelaisian grotesque and Bakhtin's study of carnivalesque.

Another example of topsy-turvy inversion can be seen in the performances and costumes of queer artist and cult personality Leigh Bowery. In one of his controversial performances, Bowery gives birth to a grown woman complete with blood and umbilical cord (see fig. 3L) while singing a rendition of "All You Need is Love" by the Beatles (Bancroft, 76-77). Again, this inversion could be classified as grotesque absurdity through the inconceivability of a person with male genitalia performing childbirth. In the grotesque costumes and art of Leigh Bowery exists a queer discourse presented as comically absurd and horrific. A common feature of his costumes can be characterized as covering the face and head partially or completely with make-up and masks (see figs. $3 \mathrm{M}, 3 \mathrm{~N}$ ) that rendered his form genderless (Ibid. 70). The perceived lack of gender adds to the absurdity and horror of a non-normative body but also showcases Bowery as 'becoming-creature' that escapes societal inscription.

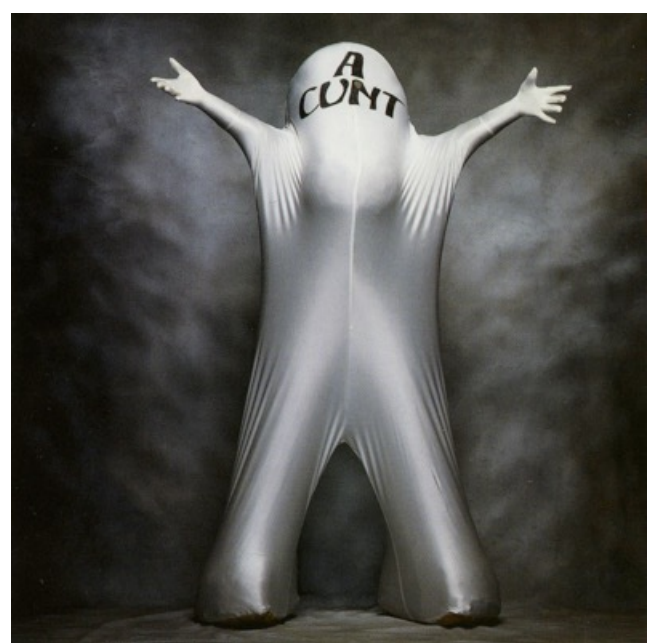

Figure 3M: Fergus Greer, Leigh Bowery / Session VI / Look 32, 1992.

Greer, Fergus, and Mariuccia Casadio. Leigh Bowery: Looks. Violette Editions, 2002.
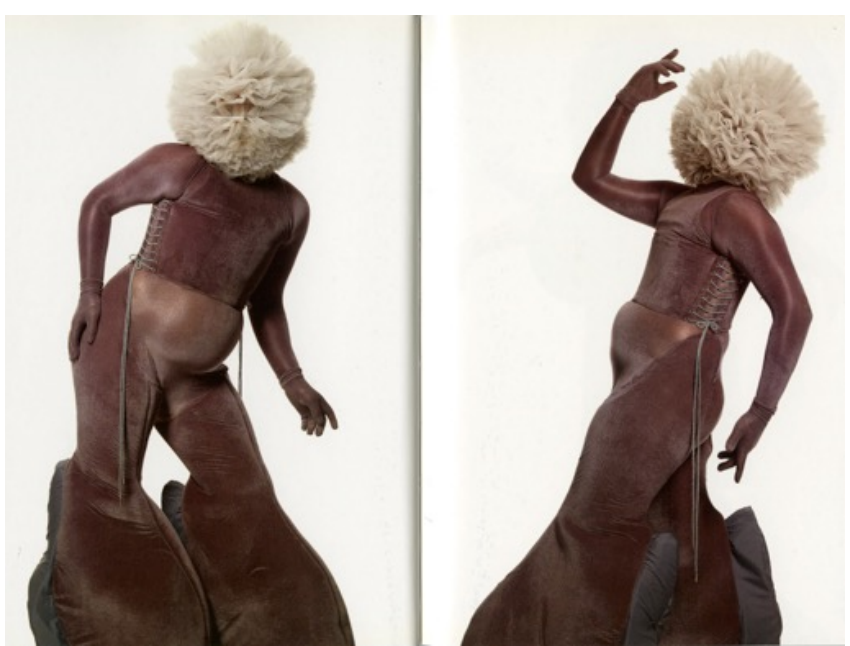

Figure 3N: Fergus Greer, Leigh Bowery / Session /I / Look 8, 1989. Greer, Fergus, and Mariuccia Casadio. Leigh Bowery: Looks. Violette Editions, 2002. 


\section{$\underline{\text { Fashion }}$}

In order to establish an MRP that fuses fashion with the grotesque to undermine mainstream normativities, it is important to discuss designers that have been pushing boundaries of normative bodies and identities. While many designers fit under this umbrella, this MRP focuses on the design houses of Comme des Garçons, Martin Margiela, and Vetements.

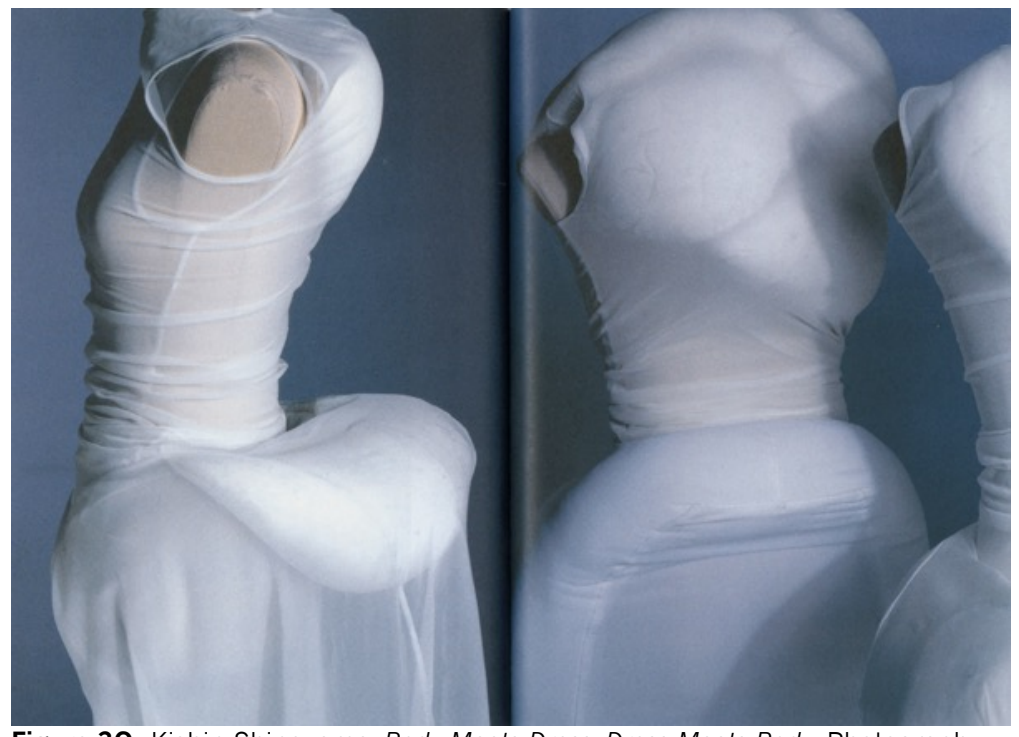

Figure 30: Kishin Shinoyama, Body Meets Dress-Dress Meets Body, Photograph, 1997.

Bolton, Andrew, and Rei Kawakubo. Rei Kawakubo: Comme des Garçons : Art of the In-Between. The Metropolitan Museum of Art, 2017.

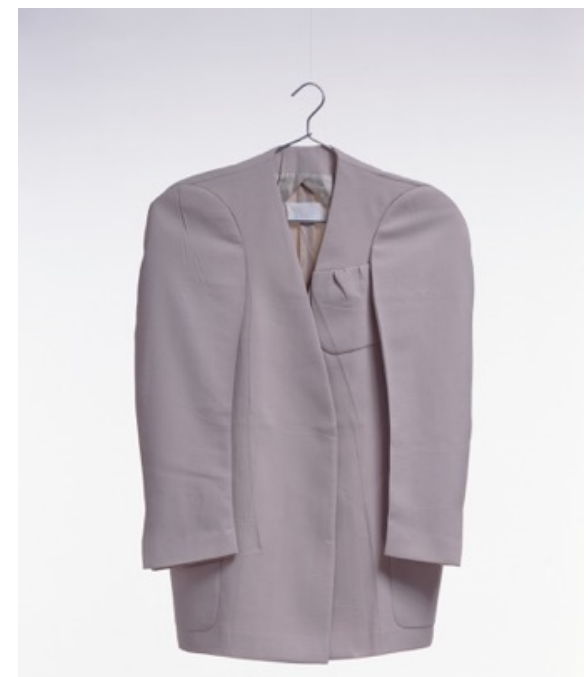

Figure 3P: Martin Margiela, Jacket, beige polyester, 1998.

Photo courtesy Takashi Hatakeyama, (c) The Kyoto Costume Institute.

http://www.kci.or.jp/en/archives/digital_archive s/1990s/KCl_289

A primary inspiration for this MRP is the Comme des Garçons Spring/Summer collection from 1997 titled "Body Meets Dress-Dress Meets Body," colloquially known as the 'Lumps and Bumps' collection (see fig. 30). Writing on what he calls affective fashion, Stephen D. Seely links this collection with the Deleuzian concept of becoming, since the collection transforms the female form into an assemblage that belies the boundary between dress and skin (249-52). Likewise, Caroline Evans discusses head designer Rei 
Kawakubo's padded creations "could be seen as speculative prototypes, or an experiment in rethinking the human creature. ... by refashioning the relationship between subject and object, between body and dress and between human flesh and soft, goose-down pads" (269). In this MRP, the shapes and materials beg to question a deformed yet humorous existence.

Martin Margiela is known for pushing the envelope in creative fashion, and has been written about extensively by Francesca Granata in her studies of Bakhtin's theory of the grotesque and carnivalesque. In Margiela's collections, the clothes toy with functionality and disrupt conventional expectations regarding what a garment should be:

observed in its disrespect for Western ideals of beauty and classical aesthetics ... experimental construction techniques, particularly using garments meant for one part of the body to clothe another, or unveiling the inside of a garment, retain a close affinity with carnivalesque techniques of inversions, travesties and upset proportions. ("Deconstruction" 185)

For Margiela, these techniques embody Connelly's belief of the grotesque as an action of play, which aims to create innovative potential among established convention and knowledge (18). The grotesque play is epitomized by garments that stylistically recur in Margiela's collections, garments where the location of specific body parts appear to shift across unimaginable planes (see fig. 3P). Thus, the body becomes presented as malformed and misshapen; a grotesque Margielan BwO.

A more recent design house that displays absurd and grotesque humour is Vetements. Absurdity exists in the name, as 'vetements' is the French word for 'clothing.' Since Demna Gvasalia, the head designer for Vetements, previously worked at Margiela, it 
is no surprise that his garments subvert conventional Western design standards similar to Margiela. Two styles that Vetements are known for are spliced denim (see fig. 3Q) and boot sock hybrids with Bic lighter heels (see fig. 3R). The denim pieces are seamed together conspicuously with the intersections slicing through pockets, cuffs, and button plackets. The resulting effect is obtrusive glitch that subverts convention. As for the high heels, there is the humorous inversion of the heel with a plastic lighter, the mystery of its load-bearing capabilities questioning reality.

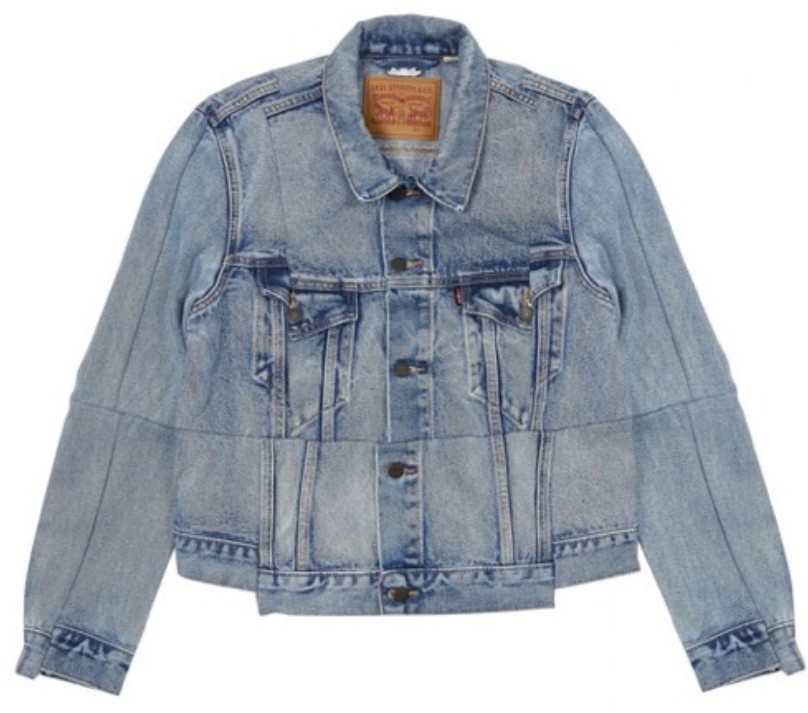

Figure 3Q: Vetements x Levi's, "Vetements Men's Reworked Denim Jacket (Blue)." https://shop.doverstreetmarket.com/vetements-men-sreworked-denim-jacket-blue

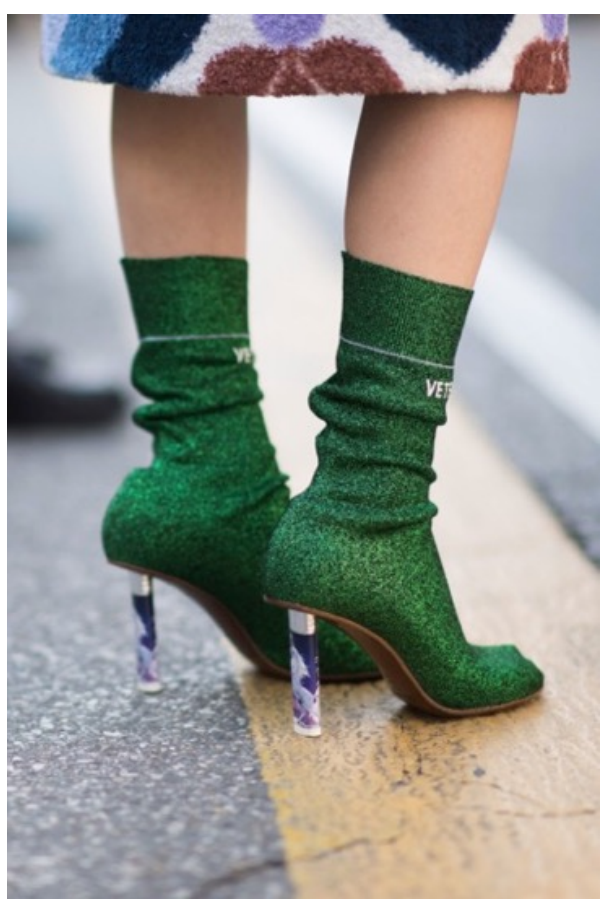

Figure 3R: Vetements Sock Boot. Photo Courtesy Getty Images.

https://www.vogue.com/slideshow/weird-heelstrend-vetements-saint-laurent-shopping - 1 


\section{Methodology}

The methodology for this creative MRP is grounded in practice-led research, which focuses on the artistic processes, iterations, and final creative artefacts. The creative work is then analyzed and interpreted through such processes with the understanding that objects can "be seen as a method of collecting and preserving information and understanding" (Mäkelä 158). This MRP creates an intersection between fashion and art, predisposing the creative work to exhibition in an interdisciplinary context and integrating theory and practice, similar to Jessica Bugg's practice-led PhD research, which aimed to configure "alternative strategies for fashion design and communication that are concept and context based, rather than being driven by commerce, the market, and trends" (10). Having a definitive queer outlook focusing on sexual identity, this creative MRP leans toward Dallas J. Baker's notion of queered practice-led research. In his article, Baker explains how queered practice-led research centers more on "subjectivities or identities" as "connection points for creative arts consumers' own subjectivities" to ensure "that the outcomes of such projects ... are accessible to general audiences" (34). Thereby situating myself reflexively and subjectively in this MRP will help make the research more approachable. For those who identify as queer, this practice-led research creative also secures a physical and visual record of the production, consumption, reinforcement, and dissemination of subjectivities (Baker 35).

Throughout all stages of the creative process, a reflexive and visual concept journal was recorded to keep track of the full creative process. Similar to a creative process journal advocated by Bill Gillham and Helen McGilp, and structured with both written notes and visual diagrams, the journal aided with the planning and execution of the artefacts (underwear), while also creating links to subsequent iterations. It has been 
valuable as a place to collect comments and feedback and to interrogate processes through theoretical lenses. After completing the final underwear, the journal remained useful in the concluding stages of analysis and outcomes and has helped to suggest areas for future exploration.

This creative MRP culminated in a fashion collection of underwear that fuses grotesque humour and a queer aesthetic utilizing the body as canvas. I rejected the notion of a collection in the traditional fashion sense, whereby pieces are culled from the same inspiration for a particular season, or are carved from an ethos that defines a brand. The collection is not based on trends or visually stylistic elements but rather connects to demonstrate a queer association with grotesque humour. In other words, the collection focuses on ambiguously discrete aspects conceivably existing under the same thematic umbrella of grotesque. Such concepts were explored through silhouette combined with texture and print and pattern. As for the conception and creation of the underwear, the process proceeded through the following developmental stages. 


\section{Creative Method}

\section{Concept Development}

To develop ideations for this MRP, digital collages were explored to investigate different shapes and silhouettes to suggest grotesque visions of the body. This process yielded five collages to inspire rough sketches that later informed the prototype development. When producing the digital collages, I restricted myself in only using images that could be found in the Photos application on my computer's hard-drive. Although these pictures may have been taken by friends and acquaintances, sometimes originating from other devices, they had to concurrently be found on my computer. A further limitation was to only use images of myself which functioned as self-reflexivity to help situate and explore my relationship with this MRP specifically, and in general how I engage with humour and grotesque. The collages were created using a mix of Adobe Photoshop and Adobe Illustrator software and culminated in a relatively cohesive visual grouping. Upon analyzing the collages, the grotesque themes that emerged dealt with the organic body, the birthed body, the feeding body, the deformed body, and the monstrous body. These themes subsequently informed rudimentary sketches of figures in profile view focused on underwear silhouettes that would be achieved.

\section{Prototype Development}

Proceeding from the sketches into the prototype process led to the development of the under-structures (items that constitute the various bulging shapes), and the draping and pattern-drafting required to fit the knit fabrics over the structures. The structures themselves consisted of both fabricated and found items. The fabricated items included resin casts of my hand and foot that were poured into silicone moulds and a 3-D print of 
my face achieved through photogrammetry. The found items included a large plastic flower pot, a vintage telephone handset, and upholstery foam that was cut and assembled to create form. Once all of the structures were acquired, draping and pattern-drafting processes were combined and executed to create the final patterns for the underwear, dependent on style and amount of stretch in final knit fabrics.

\section{Final Development \& Photo Shoot}

After finalizing the prototype underwear, the final fabrications and finishes were settled. This included all fabrics and trims (waistbands, bindings, and piping) with regard to prints, colours, and textures, and subsequently executed with all proper finishes and seam types. The final pairs of underwear were then worn by myself and documented in a photo shoot against a blank canvas. Two sets of photographs were shot: the first set taken as headless torso photographs in full colour, the second set focused on high contrast black and white shadow silhouettes in order to concentrate on shape and form versus materiality. The photographs were then sorted and refined in Adobe Photoshop into a curated series of final images. 


\section{Analysis \& Discussion}

\section{Collages}

There appears to exist a connection between queer themes and the art of collage, wherein an essential result "is the construction of new worlds and identities, the outward use of a violent action [slashing, ripping, tearing, and cutting] to protect a vulnerable inner life" (Small, "Quintessentially"). Anna Poletti further claims that collage has the power to disrupt "assumptions about representation" in spite of normative ideals (362). Therefore, as an exercise in ideation, collage is an obvious choice to explore because of its "heuristic potential" (Kilgard 6). In other words, an approach to learning and creating knowledge through hands-on activities and subsequent self-reflection on these activities. The analysis of the collages can then be used to create "resonances and connections that form the basis of discussion and learning" (K. Vaughan 40).

In the photo collages I produced, a multiplicity of themes emerged in relation to the grotesque, the queer body, and identity. The first collage (see fig. 6A) illustrates the unnatural twisting and contortion of the body from different angles to form a Cubist inspired image scrambled together from varied photographs. Jutting out from the groin are spiky and succulent cacti to create the first bulge in the series, which offers protection for the subject and concurrently evokes a sense of danger for the viewer. Furthermore, the cacti are representative of organic material that grows and inhabits the natural world. The collage is also layered with a line drawing that attempts to create depth of space while communicating to the viewer that although different, the body is still a complete being.

The second collage in the series (see fig. 6B) relies on the distortion of perspective in the presentation of the body, rather than contortion of the figure. The bulge in this 


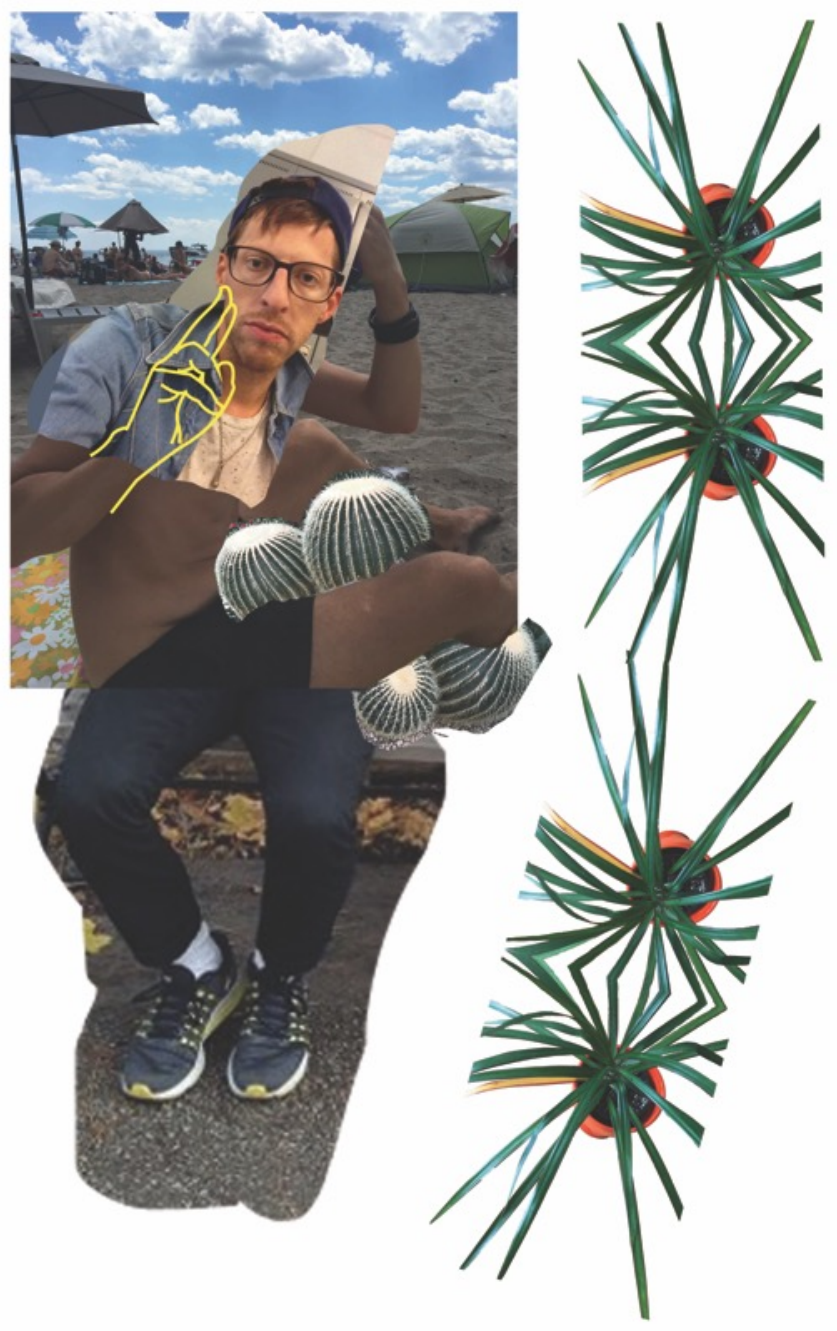

Figure 6A: Collage \#1

image has been covered with a vandalized severed baby doll head. The pointed knives floating around the figure reinforce this violence, while at the same time offering the body to the viewer in a seemingly sacrificial offering. Along with a sense of cannibalism, these elements combine with the exposed torso to convey the theme of birth, with the knives ready to sever the offspring from its parent. The arrangement of the knives in the upper portion of the composition is also reminiscent of sword swallowing performances carried out in freakish circuses, carnivals, and sideshows. 


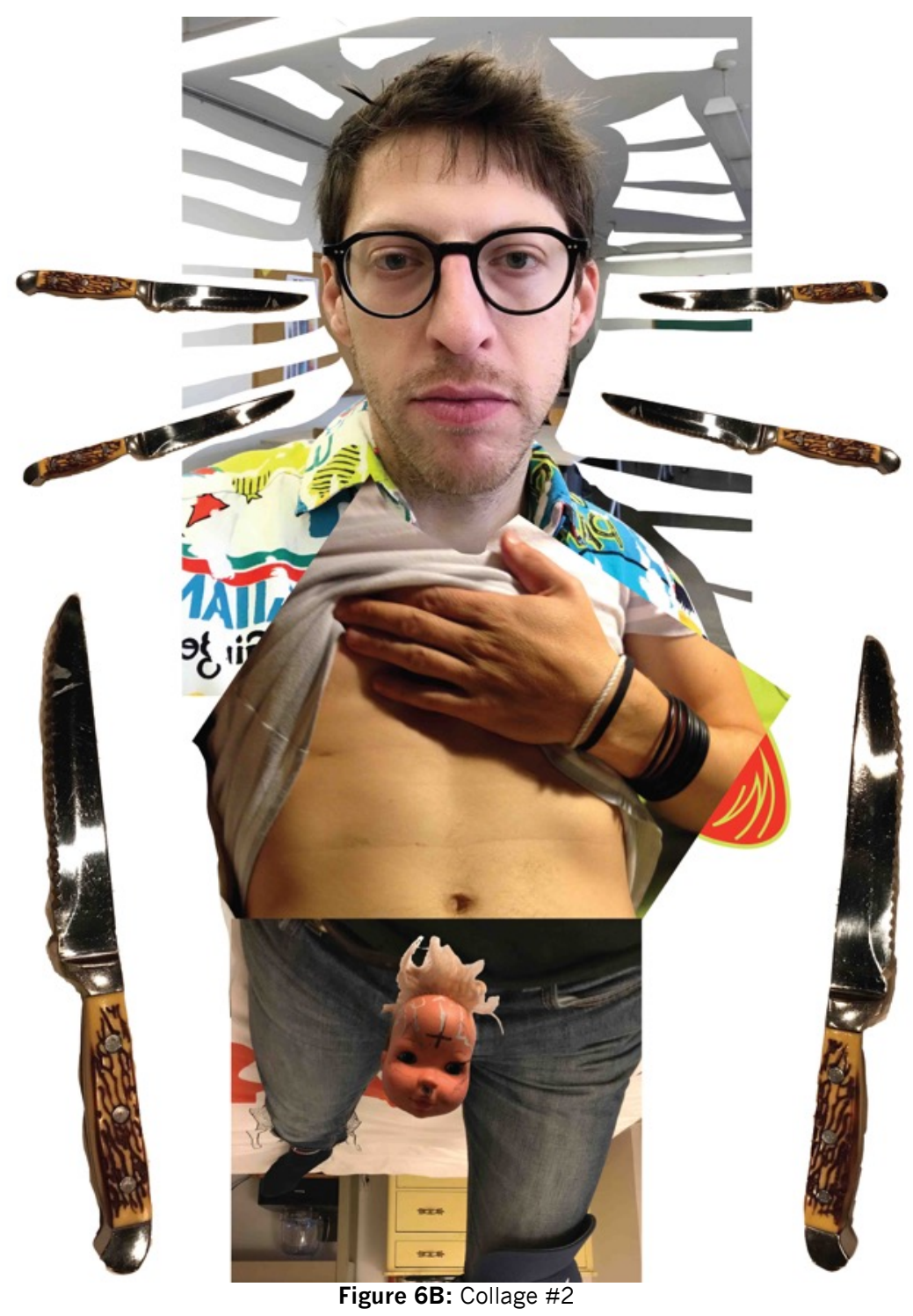

The third collage (see fig. $6 \mathrm{C}$ ) further experiments with a distorted perspective of space, but to a lesser degree than the previous. The main impact of this collage is through introducing themes of filth and decay, exemplified by the substitution of the arthritic left hand on the figure. For the bulge in this composition, onigiri, a triangular shaped rice ball commonly eaten as a snack in Japan, is superimposed onto the body. Though food is a symbol of sustenance and nutrition, it carries with it an expiration date that makes it temporal. Over time food begins to rot, eroding its quintessential feature of nourishment. 
This gruesome malodorous death attracts scavengers such as flies, and the flypaper ribbons that take up space around the figure heighten the sticky putrefaction.
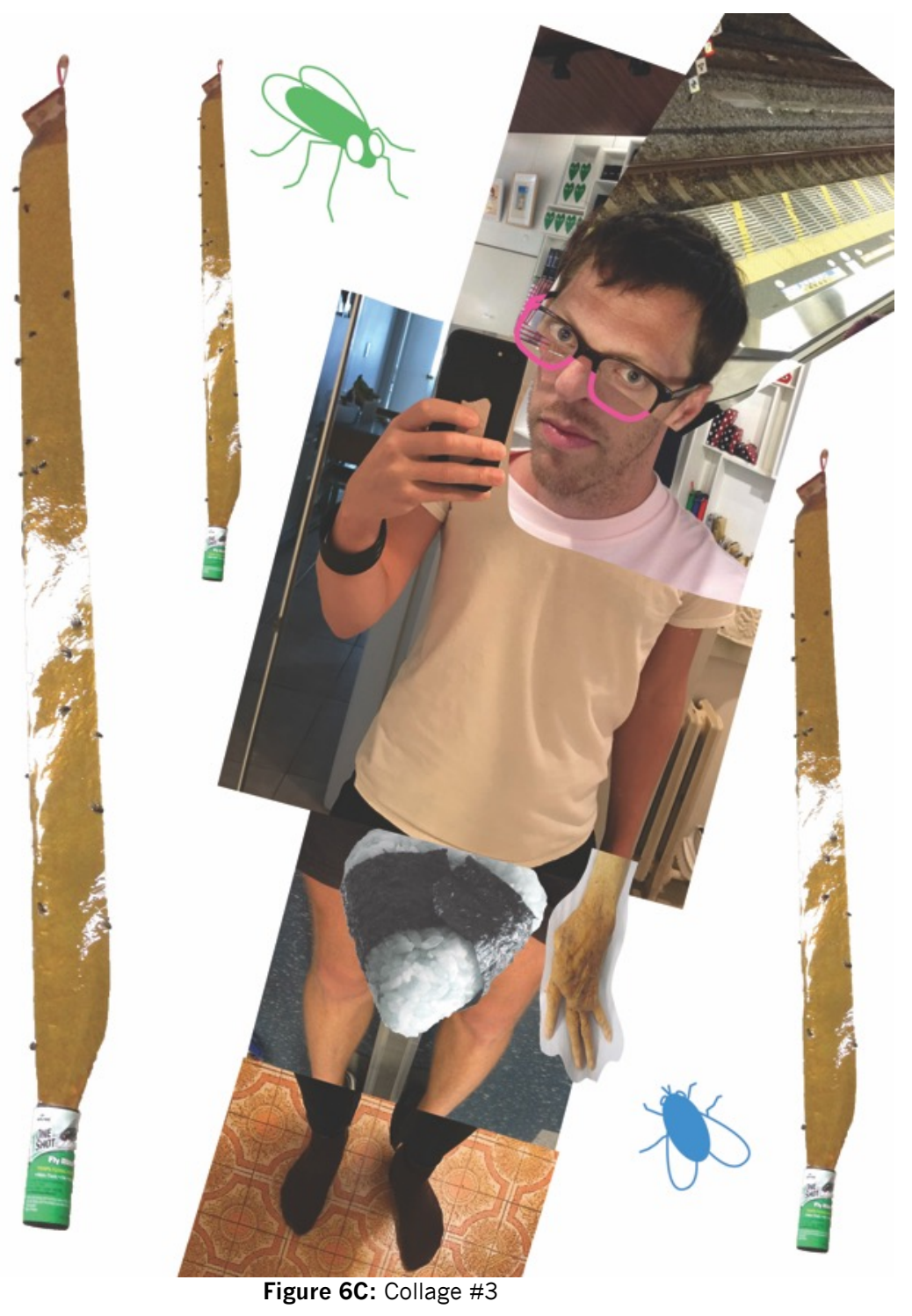

The fourth collage (see fig. 6D) deals primarily with deformity manifested in the presence of supernumerary appendages on the body, which display more than just the bulge. The amalgamation of these parts creates a body deemed inhuman, reminiscent of insects and other arthropods. Even the eyes and eyeglasses that are transposed over the face evoke a startling bug-like appearance. The repetition of parts is again echoed at the right of the composition in the duplicated chocolate cupcake under the blooming 
chrysanthemum. The many parts of this body juxtaposed with the organic flower and manufactured cupcake forces the audience to question what it means to be unnatural, even when organically occurring in the natural world. A secondary theme expressed in this collage is that of injury and pain, expressed directly as a connection between the bandaged head and the blurry lights of the background. This indirectly reinforces the pain and suffering experienced by a queer non-natural body in heteronormative and homonormative societies.
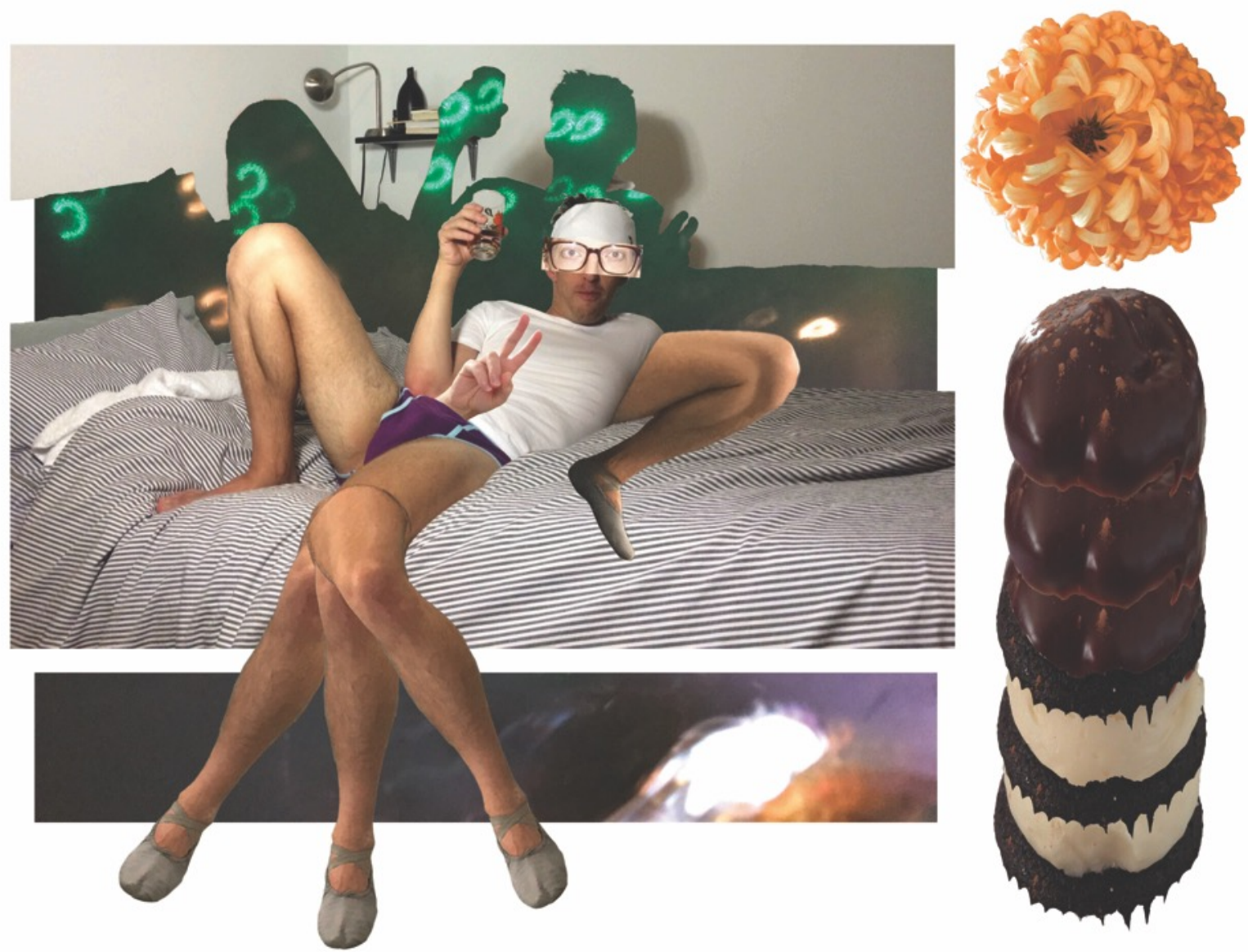

Figure 6D: Collage \#4

The fifth and final collage (see fig. 6E) suggests a monstrous transformation. The visual composition resembles the spring-like surprise of a jack-in-the-box, illustrating maturation and chrysalis. The faces that have been superimposed over the bodies have 
reversed orientations, which recollects the exorcism of demons as portrayed by Linda Blair in the Exorcist. Also, the indiscernible food present in the open mouths parallels the pupae of moths that Buffalo Bill places in his victims in the movie Silence of the Lambs. Therefore, both demonic and serial killer influences suggest the operation of beings on the fringes of society.

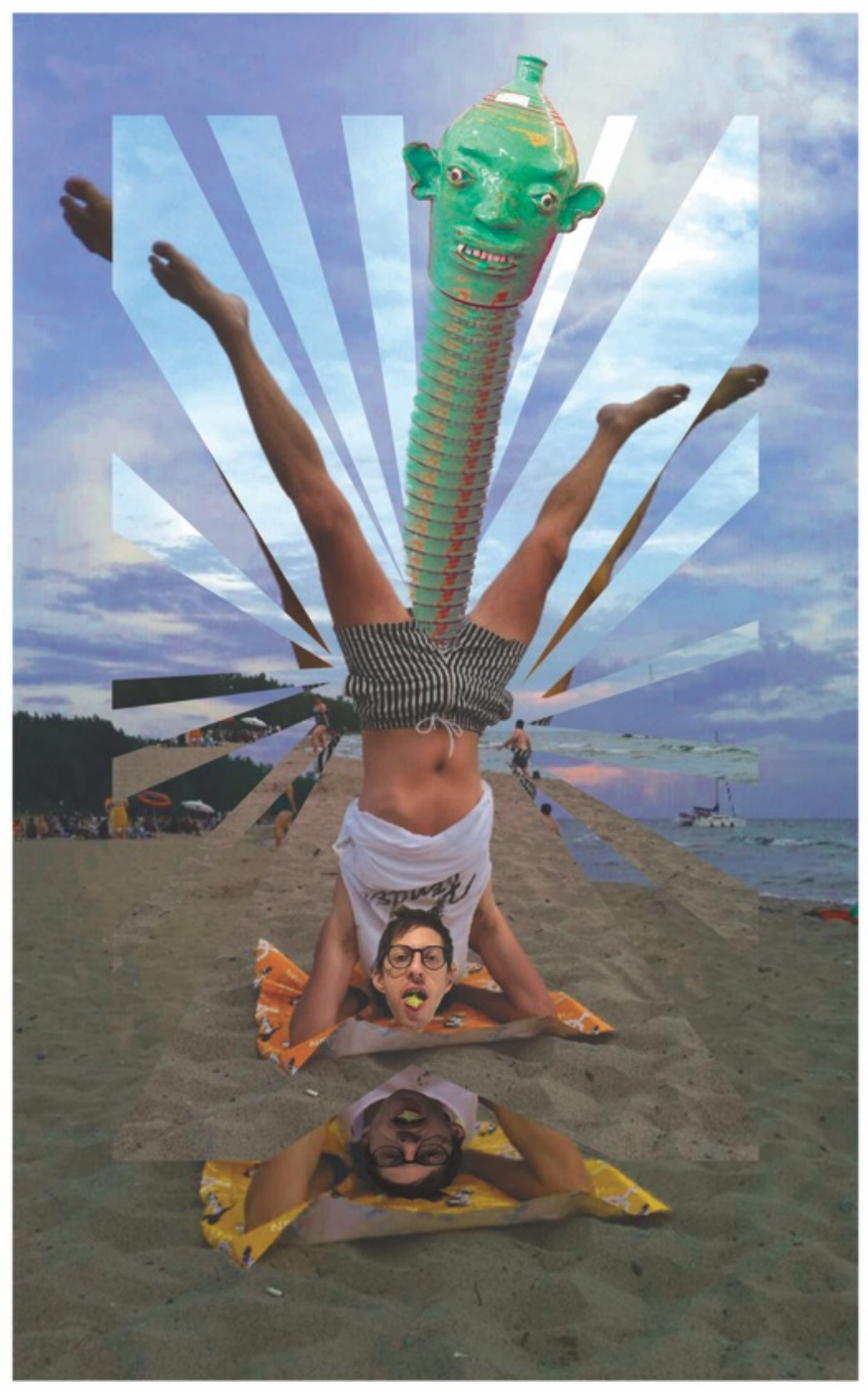

Figure 6E: Collage \#5

These collages do not just express queer themes and identities. When combined into a body of work, there is a relation to carnival, the grotesque, and the BwO. Writing on images in the media, Rebecca Coleman suggests that "images produce possibilities of 
embodiment, and become materialised in particular ways" (144). These possibilities helped to explore creativity to produce the final pairs of underwear by enabling potential flows of deterritorialization to reconfigure preconceived notions of the body.

\section{$\underline{\text { Underwear }}$}

The main themes that I decided to explore when making the pairs of underwear are natural/organic, birth/rebirth, deformity, identity, protection and the lived environment, and technology and communication. These themes were based on the rough sketches in the reflexive and visual concept journal that were explored subsequent to the collages. While the pairs of underwear explore these different themes individually, they remain connected as a whole as they reference the queer grotesque with their visual aesthetics and haptic properties. Upon analyzing the underwear, it becomes apparent that the queer grotesque is being manifested as humorous and absurd, mirroring the spirit of Bakhtin's carnival characteristics of parody and laughter in dealing with the "world turned inside out" ("Carnival" 254). The physical properties of the underwear include textiles with synthetic blends of rayon, polyester, nylon, and spandex, and all of the underwear incorporate artificially coloured contrasting bindings. The white waistbands and white stitching were chosen to accentuate the structural and supportive elements of the underwear, they are in stark contrast to the colourfulness of the other materials. Finally, the under-structures were also created/manufactured with synthetic and artificial materials that include a plastic flower planter and synthetic plants, resin casts of my hand and foot, plastic rotary telephone handset, upholstery foam, and a plastic 3-D print of my face.

The first pair of underwear (see fig. 6F) deals with ideas of birth, regeneration, and deformity. A hand is clearly visible in place of the bulge at the front of the underwear, 

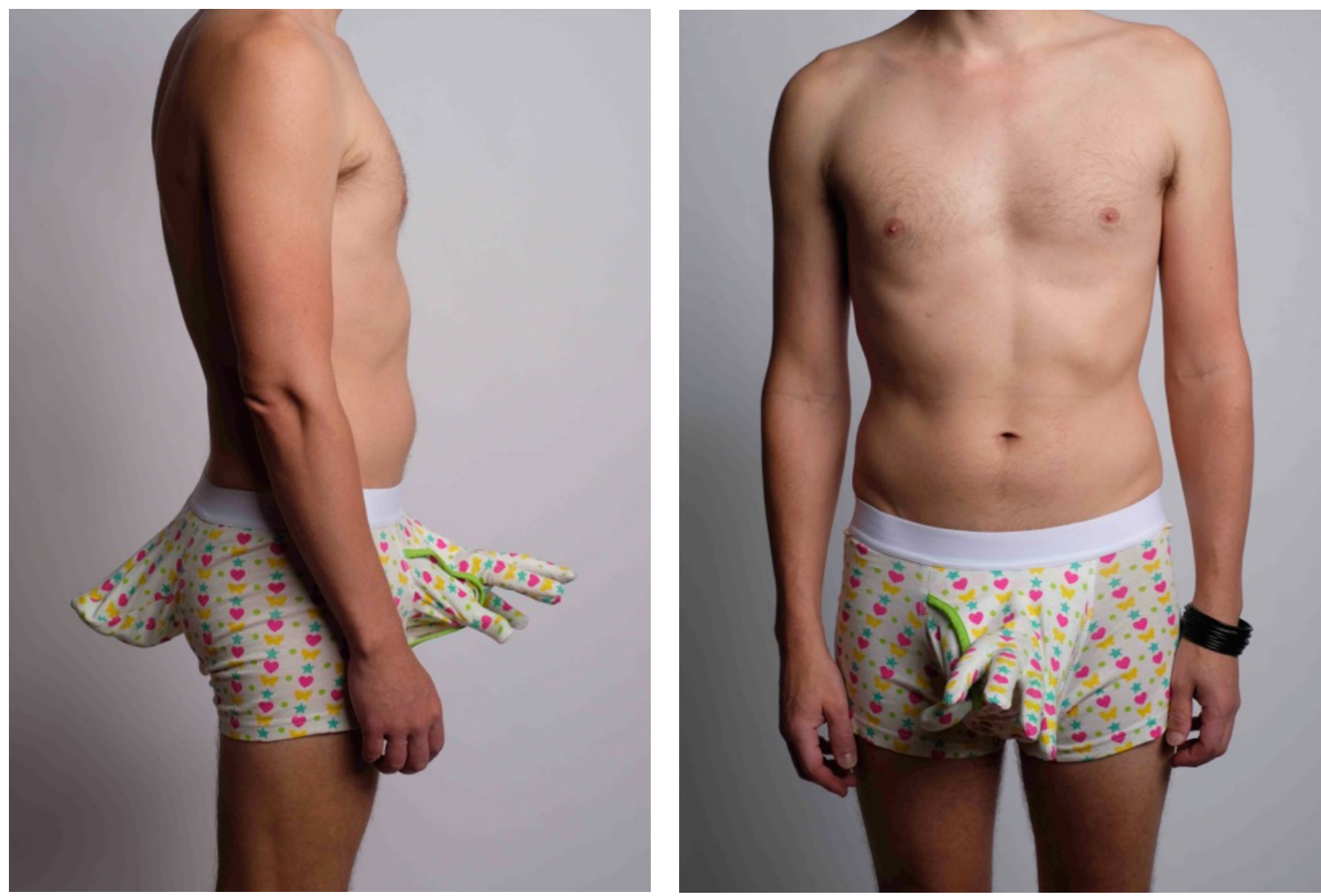

Figure 6F: Underwear \#1

protruding from beneath the fabric. From the posterior, a foot is protruding, though much less obvious and more so resembles the tail of a duck. Images of childbirth come to mind as body parts appear to emanate from the lower abdomen, similar to delivery from the womb. Here, the body can be viewed as the source of life and the infantile motifs and colours used in the printed fabric pattern reinforce the notion of childbirth. Among the motifs on the fabric are yellow butterflies suggestive of a chrysalis, maturation and perhaps an alien transformation, all processes of becoming. Alternatively, the emanation of these appendages also recall human imperfections and deformities, types of abnormalities that operate outside of mainstream culture. These imperfections defy boundaries, presenting a queer body that society seeks to contain. 

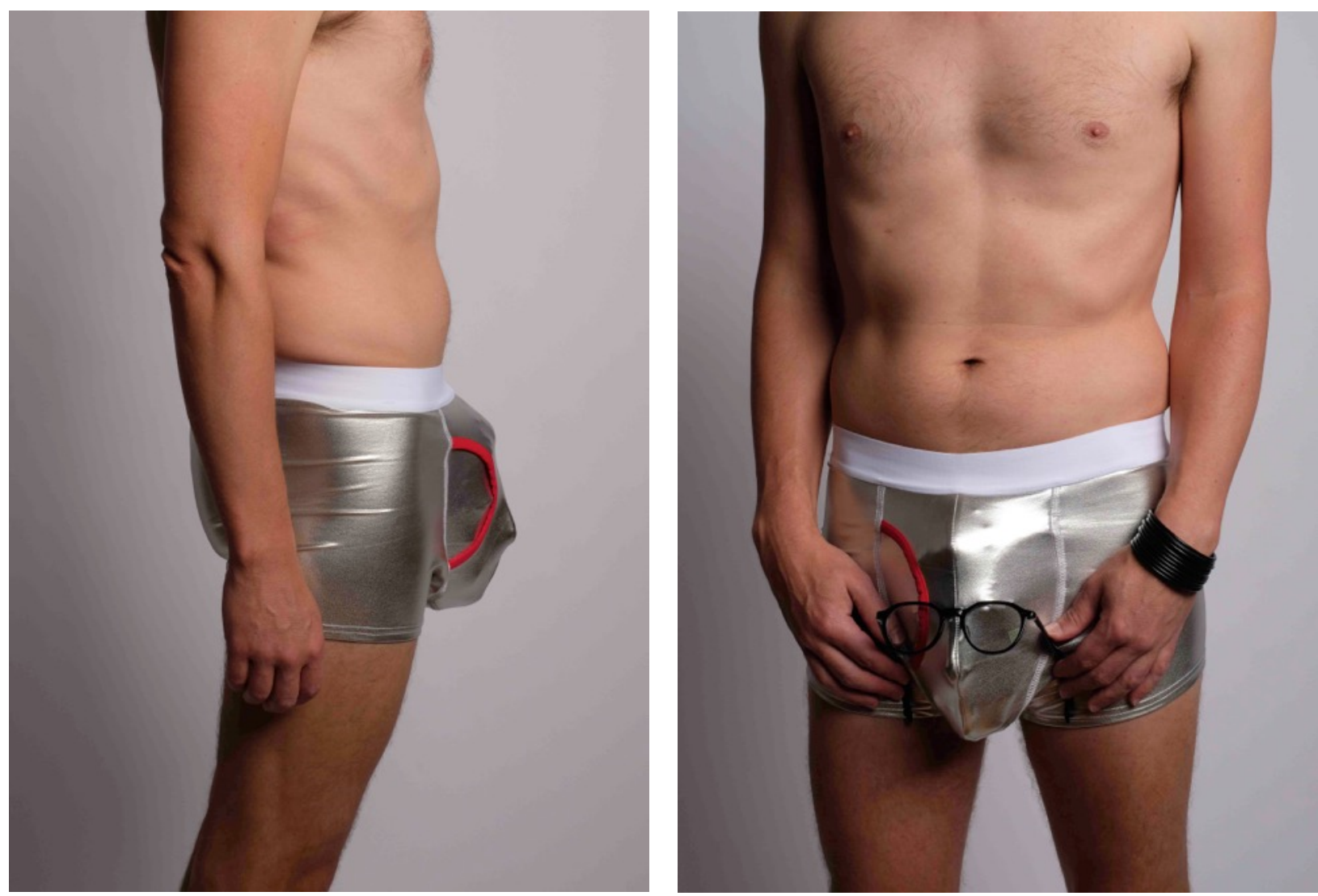

Figure 6G: Underwear \#2

The second pair of underwear (see fig. 6G) similarly deals with ideas of birth/rebirth as well as signifying an alien emanation because of the 3-D printed face that is protruding from beneath the fabric. The stretchy fabric used in the construction of this pair of underwear is bonded with a smooth silvery surface that lends a machine age aesthetic. The sense of artificial fabrication presents the cold, stiff, and unemotional attributes of a robot. This coldness operates from a place of defense against the surrounding environment, in essence a coping mechanism in the search for validation of an 'other' existence. This underwear is also a reimagining of the self since the face is an exact replication of the original that suggests cloning, self-actualisation, and a physical representation of identity. 

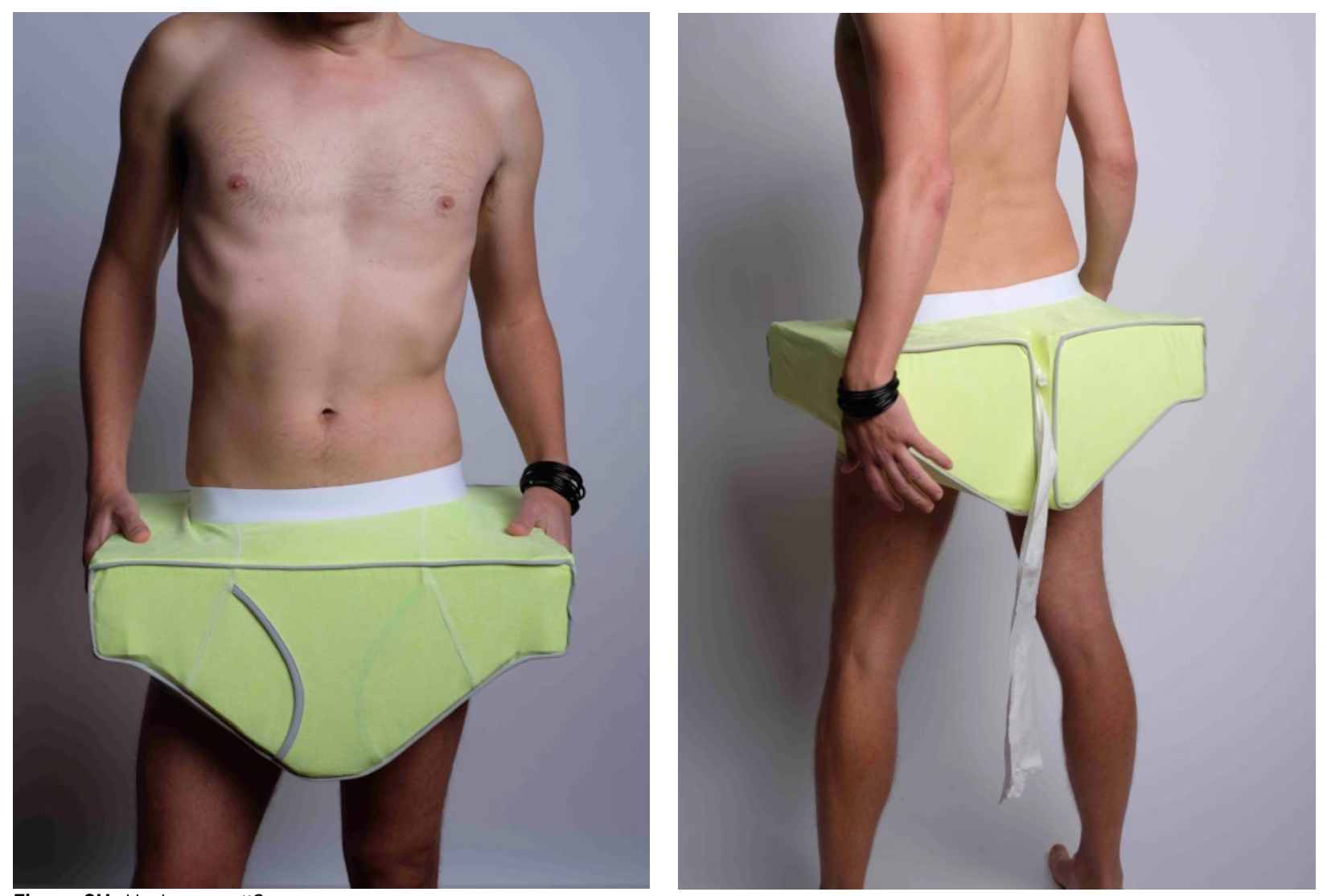

Figure 6H: Underwear \#3

The third pair of underwear (see fig. $6 \mathrm{H}$ ) is heavily abstracted by using upholstery foam to create an exaggerated geometric and hard-angled silhouette. This in turn depicts the queer body's status as an abstraction of being. The form is extremely simplified, though the shapes and construction clearly depict an alternate reality of underwear functionality. In this pair of underwear, the rigid yet plush support provided by the upholstery foam not only invokes reflection on how the queer body manoeuvres through and interacts with the lived environment, but also offers protection from the outside in its quest for a comfortable existence. In addition, the size of the underwear presents restrictive challenges to performing natural bodily functions. The fabric has a soft velvety texture and the addition of corded piping blurs the distinction between underwear and household fixture. The absurdity of this underwear is further amplified in the 
representation of the posterior as two separate couch cushions that could possibly harbor lost personal effects.
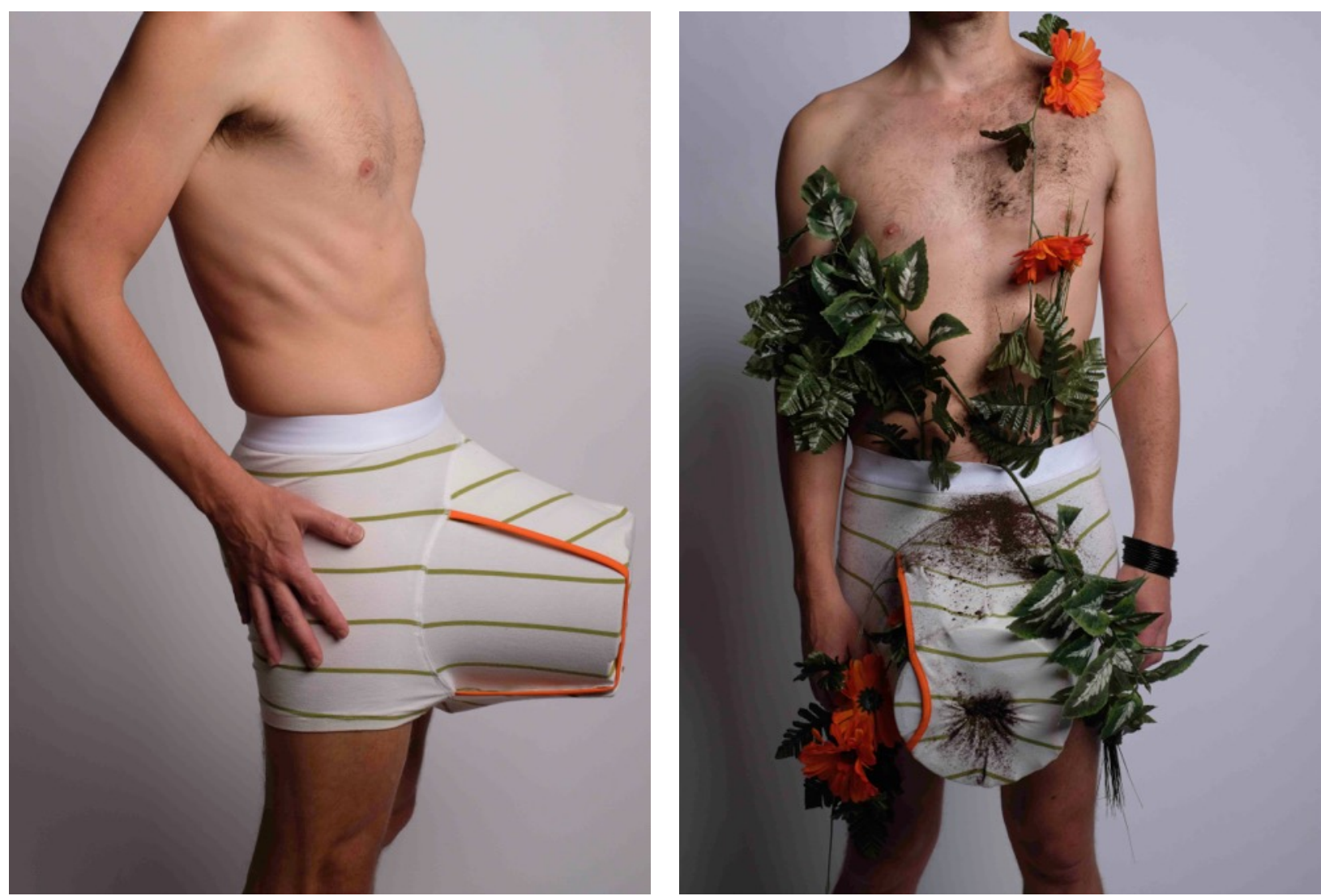

Figure 6I: Underwear \#4

The fourth pair of underwear (see fig. 6I) features a bulge that encapsulates a comically large flower planter. Protruding from the edges of the underwear are synthetic leaves, branches, and flowers that visually describe and supplement the bulge. The underwear directly illuminates the difference between the organic/natural world and the synthetic/artificial world. This polarity parallels hegemonic claims of normalcy confronted by alternative modes of being. The soil on the outside of the underwear suggests substances that leak and explode as they are expelled by the body. This waste matter that is naturally discharged by the lower bodily stratum connects to scatological humour in 
Rabelais's Gargantua and Pantagruel, which is the foundation of Bakhtin's analysis of the grotesque and carnivalesque.
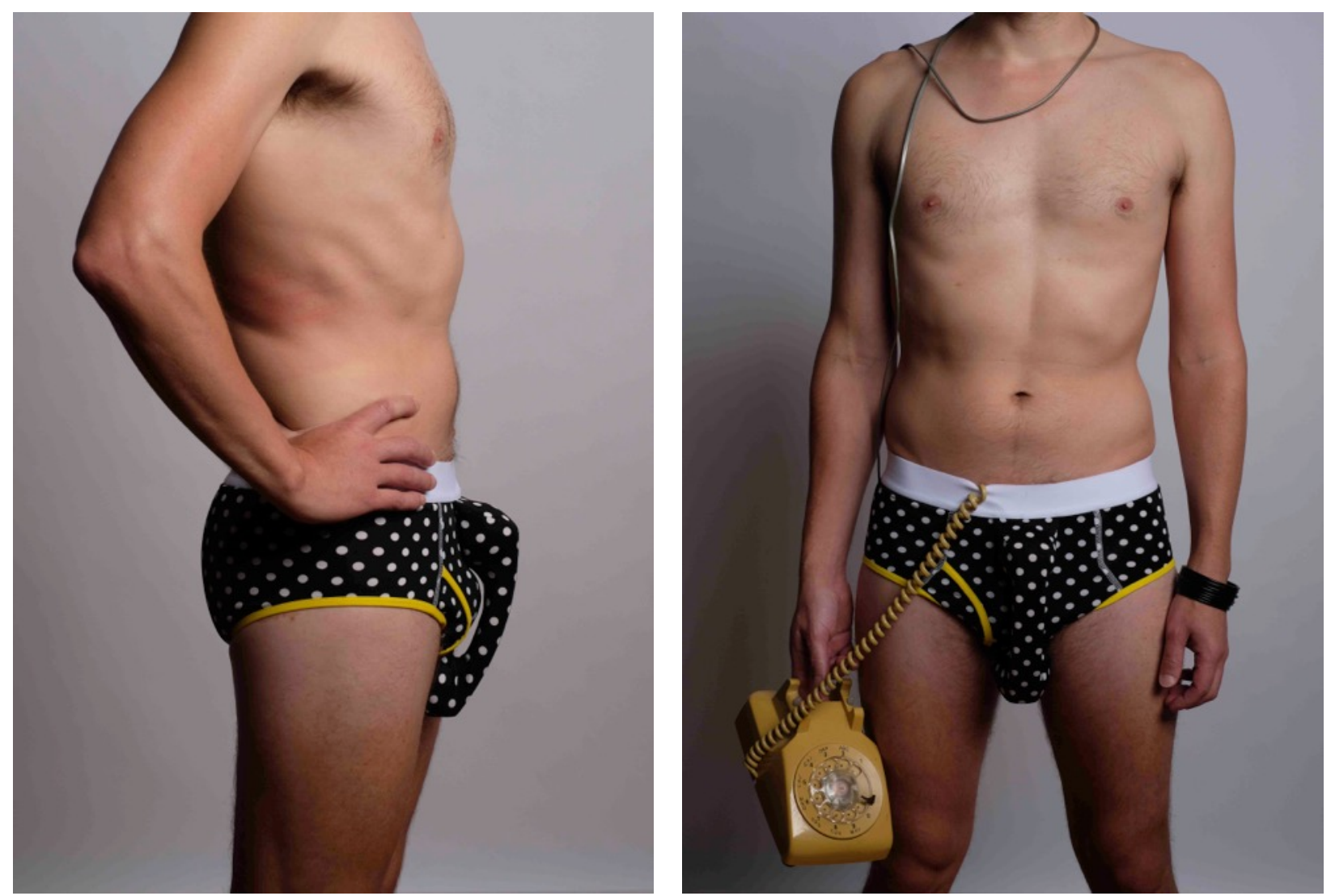

Figure 6J: Underwear \#5

The fifth pair of underwear (see fig. 6J) incorporates a vintage telephone handset into the bulge. The polka dot printed fabric mirrors the pattern of holes that can be found on the mouthpiece and earpiece of the telephone handset. The enlarged polka dots serve to magnify the porous openings of the handset that enable the user to communicate. However, this form of communication is outdated in the current technological atmosphere of texting and email. Therefore, a feeling of nostalgia for the past is evident in the contours of the iconic shape and design. In a grotesque vein, the suggestion of orifices that reveal the insides of the queer body anticipate excess and overspill from the body. 
This MRP focuses on the bulge and lower stratum to present the grotesque body. To Mikhail Bakhtin, this lower stratum is not only a source of degradation, but also that of rebirth and renewal (Rabelais $21 ; 395 ; 435)$. Rebirth and renewal are overt in the first and second pairs of underwear (see figs. 6F, 6G) as body parts emerge from unimaginable loci, i.e. the lower stratum. Depending on the point of view, there is also the potential for misrecognition as easily happens with the foot protruding from the posterior; the mistake often culminating in comedic response. The third and fourth pairs of underwear with the upholstery foam and flower pot (see Figs. $6 \mathrm{H}, 6 \mathrm{I}$ ) evoke grotesque humor in their preposterousness by expanding the perimeter of the body to exaggerated proportions. Bakhtin summarizes Heinrich Schneegans by stating "The exaggeration of the inappropriate to incredible and monstrous dimensions is ... the basic nature of the grotesque. Therefore, the grotesque is always satire" (Rabelais 306). With the exception of being grotesquely quizzical, the fifth pair of underwear with the telephone handset (fig. $6 \mathrm{~J}$ ) remains to have the least connection with the others in the series when it comes to Bakhtin's theories. However, the holes in the handset as previously mentioned abound with trypophobic anxiety, which is the irrational fear of holes clustered together.

The reorganization of the body is essential to Deleuze and Guattari's Body without Organs (BwO), and for this MRP the $\mathrm{BwO}$ is examined primarily in relation to the male bulge of the lower front torso. Not to be assumed literally as a body devoid of organs, nor a body that encompasses a/some indeterminate organ(s), the $\mathrm{BwO}$ is an unfixed temporal body of determinate organs (Deleuze 42). This allows the body to become deterritorialized, since the $\mathrm{BwO}$ is against the organization of the organism. "Movements of deterritorialisation ... have the potential to shift the ways in which a social ethics can be understood and enacted" (Harold qtd. in Malins 176). Since the queer body might be 
considered unproductive (reproductively) and not fit for consumption as deemed by heteronormative ideologies, the $\mathrm{BwO}$ is useful in considering the queer body's potentials to exist. Therefore, it is paramount to understand what the new and/or reorganized parts (organs) created during this MRP are capable of doing.

In the first pair of underwear (see fig. 6F), the bulge has been given the potential to grasp and to hold, and the posterior has been given the ability to walk and kick. In the second pair of underwear (see fig. 6G), the bulge has been given the abilities of sight, smell, sound. It can taste, swallow, and breathe, all requirements for a proper body to subsist and exist. While both of these pairs of underwear produce different ways for the body to live and know the world, the bulge of the third pair of underwear (see figs. $6 \mathrm{H}$ ) extends around the body, protecting the $\mathrm{BwO}$ with thick padding, which allows the body to take risks in its threatening habitat. The bulge of the fourth pair of underwear (see fig. 6I) is representative of the determinate organ that expels waste (soil), ridding the $\mathrm{BwO}$ of impurities to survive as a fully functioning being. While the bulge of the fifth pair of underwear may be viewed as phallic (see fig. $6 \mathrm{~J}$ ), it takes the biggest departure from the BwO structure since it is an inorganic representation. Its function within the body's system is to communicate. Such communication may be in the relay of truths or the spread of gossip, though along with all other BwO's, its major purpose must be employed to create potentials and flows of deterritorialization to upset normativity.

"The grotesque image reflects a phenomenon in transformation, an as yet unfinished metamorphosis, of death and birth, growth and becoming" (Bakhtin, Rabelais 24). This statement reveals some of the ways that a queer body resists normativity, through constant change, adaptation, and evolution. It should also be recalled that grotesque is always satire, and from this satire I have hoped to inject humour to illuminate 
traditional hegemonic narratives throughout this MRP. As mentioned previously, reorganization is central to the $\mathrm{BwO}$, which challenges "normative images of what a body should look like ... [therefore] identity can become more fluid and flexible" (Smelik 172). Accordingly, the employment of a queer $\mathrm{BwO}$ enables minorities to reject and transcend oppressive values and beliefs enacted in the status quo.

Heteronormative ideologies capitalize on the subjugation of minorities. In addition, there is an equally oppressive force within gay culture termed homonormativity, described by Lisa Duggan in 2003 as "a politics that does not contest dominant heteronormative assumptions and institutions, but upholds and sustains them" (50). This basically attempts to forge a widely-accepted image of homosexuality that conforms and is controlled by society, while ignoring the breadth of lived experiences that do not fit this mold. Academic Gavin Brown similarly finds homonormativity problematic, claiming that it "leaves little space for seeing practices that operate outside of, or counter to its logics" (1067). Therefore, homonormativity creates pressures to conform, and along with this conformity, it manifests itself in the physical by idealizing a certain type of beauty and physique, while commending the affordances of those that can attain such ideals. With this MRP I want to challenge what scholar Mitchell Wood refers to as gendered body aesthetics, which connect to homonormative masculinities of how a gay male body should present. Through the creation of underwear in the MRP, I sought to subvert homonormative ideologies through humour that questions the validity of a naturalized gay ideal. I did this by transforming the bulge in grotesque, humorous, and shocking ways. As another way to tackle homonormativity, I curated the underwear photographs as headless torso images similar to those found on gay dating apps, which are often used to find instant sexual partners in close proximity to the user. On these such apps, a lot of 
attention is paid to the gendered body aesthetics of fit and muscular bodies, and the prominence of the male bulge. For this reason, my intention is to mock the presentation of these bodies that fall prey to homonormative masculinities, and as a result, open up space for bodies that these normative ideals marginalize.

I decided to explore fashion for this creative MRP because of its connection to identity and the body. According to Joanne Entwistle, "not only does dress form the key link between individual identity and the body ... dress is fundamentally an inter-subjective and social phenomenon, it is an important link between individual identity and social belonging" (337). This means dress is both mediated by the self (body/identity), as well as the social and cultural environments where it exists. Entwistle continues: "social pressure encourages us to stay within the bounds of what is defined in a situation as 'normal' body and 'appropriate' dress" (338). Since there are inherent forces within society that supply such pressures to be 'normal' and 'appropriate,' fashion can be a suitable practice to transgress and subvert these suppositions. In addition, when confronted with hegemonic ideologies, oppressed and subjugated people often turn to dress as protest and resistance. Shaun Cole and Reina Lewis further explain:

Dress has long been acknowledged as a formative element of the ways in which queer (LGBTQ) cultures become visible and legible to 'queer' people themselves and to external societies [and dress can] play a uniquely significant role in the formation, acceptance and public dissemination of non-normative sexual identities. (149)

Therefore, since fashion represents identity and can be used as a tool of transgression and resistance, it makes an appropriate practice for this MRP. 
Under the scope of fashion, I focused on creating underwear for its numerous purposes and symbolic properties. Underwear provides structure and support, security, promotes clean hygiene, and also functions as expressions of gender, sexuality, erotic desire, and fetish. In order to challenge and subvert norms, the underwear I created disrupts the conventional purposes and symbols of underwear by ignoring these functions. By creating unpredictable silhouettes that resemble avant-garde and high fashion, the silhouettes are not something ready for mainstream consumption. For example, whereas underwear should normally act as support for the male genitalia, much of the underwear in this MRP protrudes away from the body, not offering the usual level of support expected. In addition, by not clinging to the body, an instability is created as portions of the underwear move on their own, altering the body's movement through, and perception of, space. Entwistle states "our body is not just the place from which we come to experience the world; it is through our bodies that we come to see and be seen in the world" (334). Through analyzing this "embodied practice" of wearing the underwear, the body can be viewed as subversive, non-conforming, disregarding convention, and appealing to derision and ridicule. Lastly, the underwear simultaneously presents an opportunity for reflection and reflexivity among the audience, which can help express and convey stories of marginalized people.

\section{Silhouettes}

The final stage of this creative MRP culminated in high contrast black and white silhouettes of the pairs of underwear projected onto a screen as they were worn during a photo shoot. The silhouettes (see figs. $6 \mathrm{~K}, 6 \mathrm{~L}, 6 \mathrm{M}$ ) directly recall and reinforce the nature of the grotto, to which the term grotesque owes its roots. 
It is earthy and material, a cave, an open mouth that invites our descent into other worlds. It is a space where the monsters and marvels of our imagination are conceived. While the grotesque pulls us beyond the boundaries of the world we know, it also reminds us of our limits and our own mortality. (Connelly 1 ).
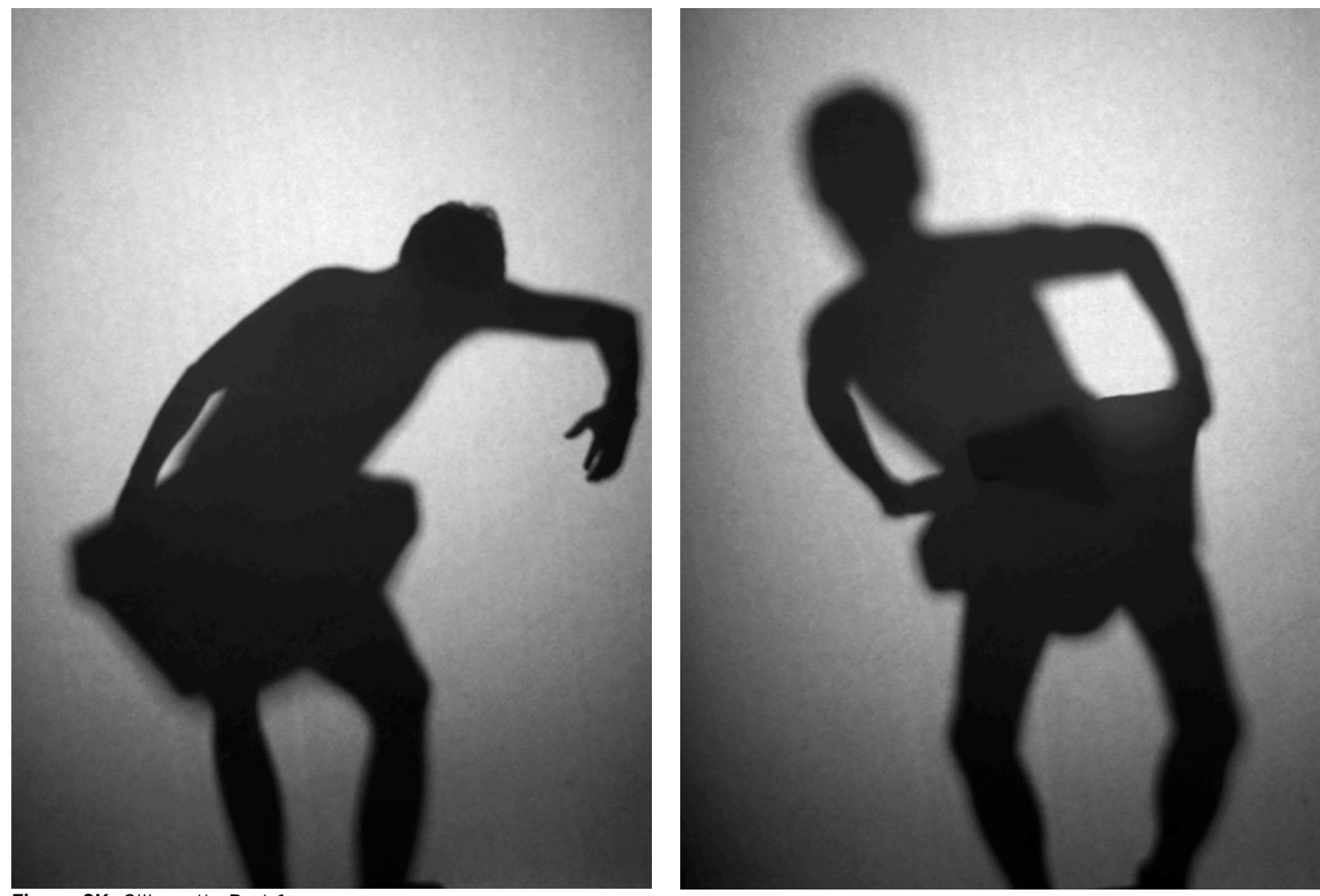

Figure 6K: Silhouette Part 1

Distilling all life of light and colour into a dimly lit achromatic backdrop redolent of the cave, these images render the underwear imperceptible. What is left protruding is that which lies beneath the surface: monstrous, creepy, and evil. It reflects our darkest fears while simultaneously eliciting subconscious desires presenting an amount of disturbance that makes it difficult to look away. The silhouettes fulfill the purpose of the grotesque "by prying open a gap, pulling us into unfamiliar, contested terrain" "it ruptures the boundaries of what we "know'” (Connelly 2; 8). The strange and monstrous shapes of the 
silhouettes add to the unfamiliar hybrid bodies that tug at cultural anxieties. These same grotesque bodies are often used by societal hegemonies to reinforce ideas of difference and deviation (Edwards and Graulund 45).
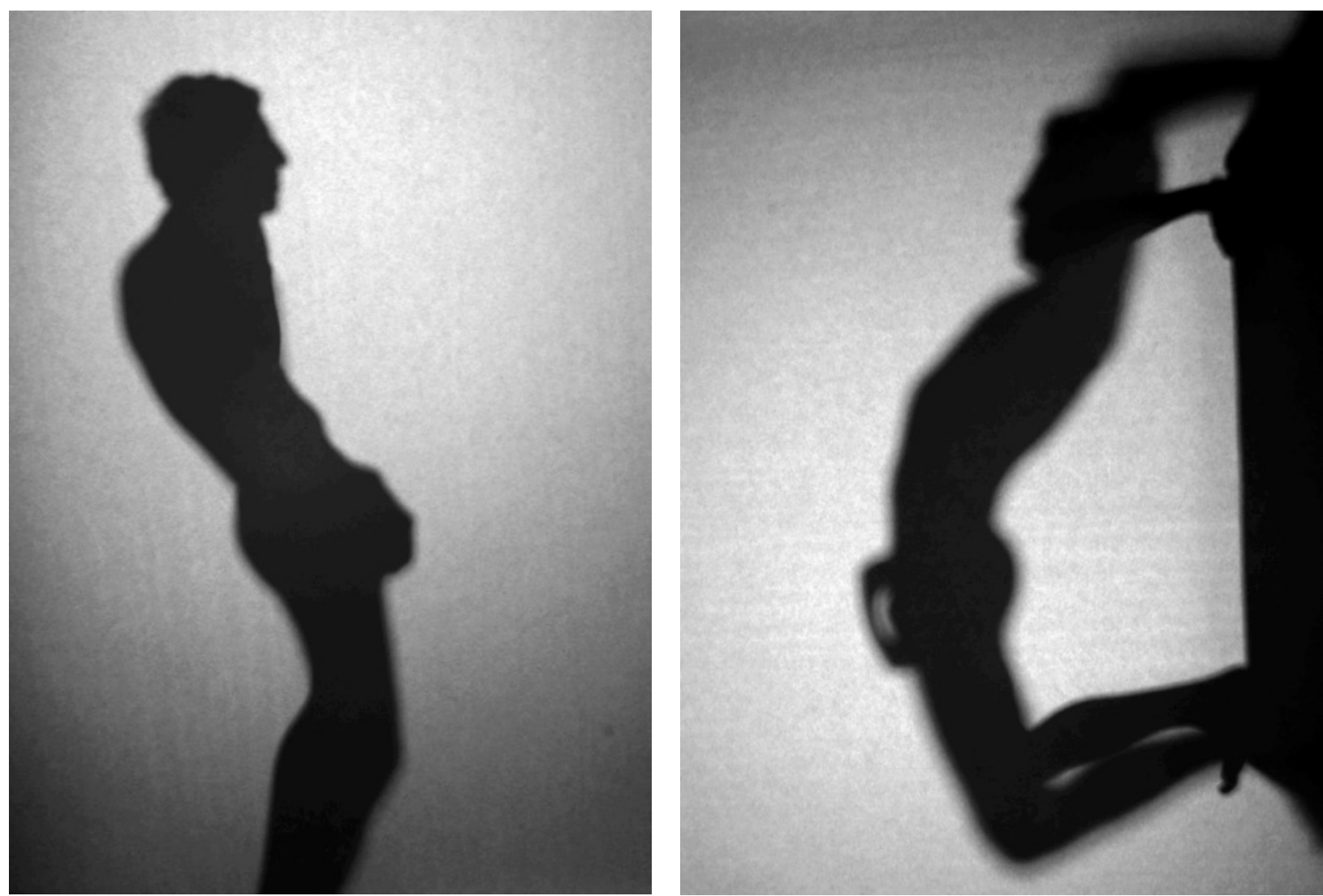

Figure 6L: Silhouette Part 2

These silhouettes also strongly link to the concept of carnival, a time of festival and spectacle when the world of everyday suspends and inverts into a world of upside-down and reverse (Bakhtin, "Carnival" 250-51). While Bakhtin maintains that the tradition of carnival has nearly vanished since its popularity in the seventeenth century (Ibid. 258), its residue still carries over into Western festivities during All Hallows' Eve and in masquerade. It is a time to escape the fixed body of the self, giving way to the potential to inhabit irregular forms. "This temporary suspension, both ideal and real, of hierarchical rank created during carnival time a special type of communication impossible in everyday life" 
(Bakhtin, Rabelais 10). These suspensions from everyday life and flows of potential again reflect a Deleuzian BwO that is, borrowing the title of Antonin Artaud's radio play that gave birth to the BwO, To Have Done with the Judgement of God. In other words, allowing an existence to be free from the forces of judgement and restraint.
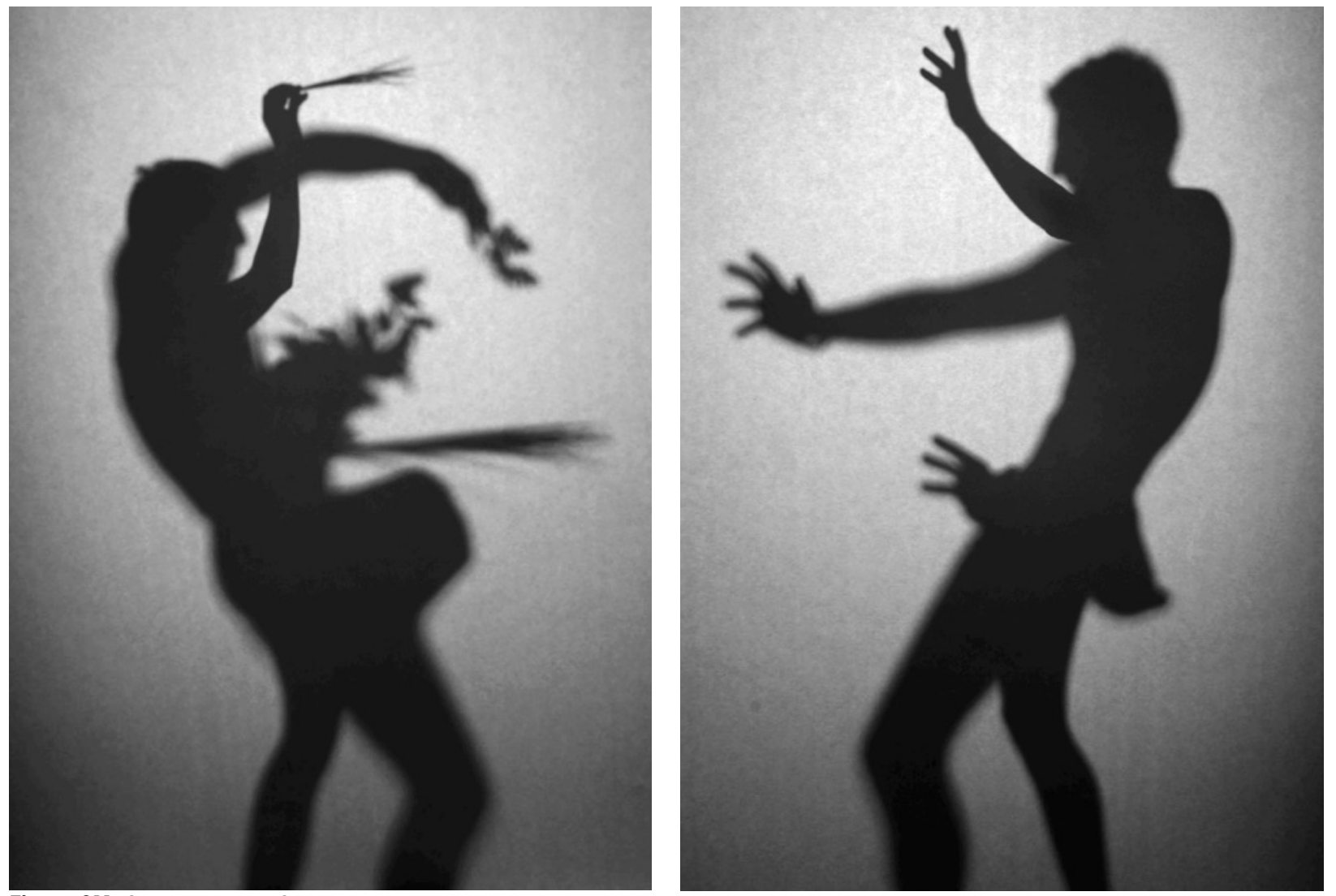

Figure 6M: Silhouette Part 3 


\section{Connections, Results, \& Future Development}

Relying on a practice-based research method of approach for this creative MRP, I concluded with several outputs that all seek to inform the relation between the queer body and grotesque humour. This relationship was then expounded regarding the queer body and its affects from normative ideologies and hierarchies, both hetero- and homonormativities in turn. The outputs included digital collage, fabric underwear, and a series of photographs (full colour underwear, and black and white body silhouette). Thus, the MRP moved along a planar trajectory from two-dimensional to three-dimensional and back again.

The different outputs were then used to qualify the manner in which queer bodies subvert hegemonic ideologies that confer the idea of normal on society. While not overtly explicit, the role of fashion also helped to provide context throughout this MRP to the body and its transgressive resistance. In this instance, I consider the term fashion to encompass the dressing and adornment of the body, and not specific modes that revolve around currency and trends.

One future endeavor that could grow out of this MRP would be to further analyze the queer body through the philosophies of Deleuze and Guattari in an attempt to align the queer body as schizophrenic par excellence. As it stands, this MRP barely scratches the surface in terms of Deleuzian thought, which extends far beyond the concepts of the BwO and becoming. Regarding the grotesque and the carnivalesque, this MRP could be expanded to include many more examples that further elucidate the connections between the queer and the grotesque, not only relying on underwear and still photography, but utilizing other media such as film. This type of MRP could also support deeper 
investigations within other minority communities to transgress normative ideologies and create new ways of knowing. Finally, with the myriad of emerging fashion that tests the boundaries of normative ideals and behaviours, it would be interesting to find a way to measure the connections between concepts of the grotesque and inevitable creative output. 
Works Cited

Alien. Directed by Ridley Scott, performances by Sigourney Weaver, Tom Skerritt, and John Hurt, Twentieth Century Fox, 1979.

Baker, Dallas J. “Queering Practice-Led Research: Subjectivity, Performative Research and the Creative Arts." Creative Industries Journal, vol. 4, no. 1, 2011, pp. 33-51. Taylor \& Francis Online, DOI: 10.1386/cij.4.1.33_1.

Bakhtin, Mikhail. Rabelais and His World. Translated by Hélène Iswolsky, Indiana UP, 1984.

—. "Carnival and Carnivalesque." Cultural Theory and Popular Culture: A Reader. $2^{\text {nd }}$ ed. Ed. John Story. University of Georgia Press, 1998, pp. 250-59.

Bancroft, Alison. "Leigh Bowery: Queer in Fashion, Queer in Art." Sexualities, vol. 15, no. 1, 2012, pp. 68-79. Scholars Portal, DOI: 10:1177/1363460711432102.

“Becoming, n." OED Online. Oxford University Press, 2017. www.oed.com/view/Entry/16788. Accessed 12 Oct. 2017.

Blanco F., José. "Revealing Myself: A Phenomenological Approach to My Underwear Choices through the Years." Critical Studies in Men's Fashion, vol. 1, no. 2, 2014, pp 117-31. Ingenta Connect, DOI: 10.1386/csmf.1.2.117_1.

Brown, Gavin. “Homonormativity: A Metropolitan Concept that Denigrates 'Ordinary' Gay Lives." Journal of Homosexuality, vol. 59, no. 7, 2012, pp. 1065-72. Scholars Portal, DOI: $10.1080 / 00918369.2012 .699851$.

Bugg, Jessica. "Fashion at the Interface: Designer-Wearer-Viewer." Fashion Practice, vol. 1, no. 1, 2009, pp. 9-32. Taylor \& Francis Online, DOI: 10.2752/175693809X418676. 
Butler, Judith. "Performative Acts and Gender Constitution: An Essay in Phenomenology and Feminist Theory." Theatre Journal, vol. 40, no. 4, 1988, pp. 519-31.

Cole, Shaun. "Considerations on a Gentleman's Posterior." Fashion Theory, vol. 16, no. 2, 2012, pp. 211-34. Taylor \& Francis Online, DOI:

10.2752/175174112X13274987924131.

—. The Story of Men's Underwear. Parkstone International, 2010.

Cole, Shaun, and Reina Lewis. "Seeing, Recording and Discussing LGBTQ Fashion and Style." Fashion, Style \& Popular Culture, vol. 3, no. 2, 2016, pp. 149-55. Ingenta Connect, DOI: 10.1386/fspc.3.2.149_7.

Coleman, Rebecca. "'Be(come) Yourself only Better': Self-transformation and the Materialisation of Images." Deleuze and the Body. Eds. Laura Guillaume and Joe Hughes. Edinburgh UP, 2011, pp. 144-64.

Connelly, Frances S. The Grotesque in Western Art and Culture: The Image at Play. Cambridge UP, 2012.

Deleuze, Gilles, and Félix Guattari. Anti-Oedipus: Capitalism and Schizophrenia. Translated by Robert Hurley, Mark Seem, and Helen R. Lane, University of Minnesota Press, 1983.

—. A Thousand Plateaus: Capitalism and Schizophrenia. Translated by Brian Massumi, University of Minnesota Press, 1987.

Duggan, Lisa. The Twilight of Equality?: Neoliberalism, Cultural Politics, and the Attack on Democracy. Beacon Press, 2003. 
Edwards, Justin D., and Rune Graulund. Grotesque. Routledge, 2013.

Entwistle, Joanne. "Fashion and the Fleshy Body: Dress as Embodied Practice." Fashion Theory, vol. 4, no. 3, 2000, pp. 323-48. Taylor \& Francis Online, DOI: $10.2752 / 136270400778995471$.

Evans, Caroline. Fashion at the Edge: Spectacle, Modernity \& Deathliness. Yale UP, 2003.

Gillham, Bill, and Helen McGilp. "Recording the Creative Process: An Empirical Basis for Practice-Integrated Research in the Arts." International Journal of Art \& Design Education, vo. 26, no. 2, 2007, pp. 177-84. Scholars Portal, DOI: 10.1111/j.14768070.2007.00527.x.

Granata, Francesca. "Deconstruction Fashion: Carnival and the Grotesque." Journal of Design History, vol. 26, no. 2, 2013, pp. 182-98. Scholars Portal, DOI: 10.1093/jdh/eps050.

—. "Mikhail Bakhtin: Fashioning the Grotesque Body." Thinking Through Fashion: A Guide to Key Theorists. Eds. Agnès Rocamora and Anneke Smelik. I.B. Tauris, 2016, pp. 97114.

-. Experimental Fashion: Performance Art, Carnival and the Grotesque Body. I.B. Tauris, 2017.

Hillcrest Swimwear. hillcrestswimwear.com. Accessed 23 Oct. 2016.

Hinkson, Kamila. “Queen's University Student's Underwear Art Deemed 'Inappropriate' for Donor Event." Toronto Star, 3 June 2013, 
www.thestar.com/news/canada/2013/06/03/queens_university_students_underwe ar_art_deemed_inappropriate_for_donor_event.html. Accessed 23 Oct. 2016.

Joffe, Bruce H. "Skivvies with the Givvies: Vintage American Underwear Ads Feature Sexual Innuendo between "Boys" in the Brands." Textile, vol. 6, no. 1, 2008, pp 4-17. Academic OneFile, DOI: 10.2752/175183508X288662.

Kilgard, Amy K. "Collage: A Paradigm for Performance Studies." Liminalities: A Journal of Performance Studies, vol. 5, no. 3, 2009. http://liminalities.net/5-3/collage.pdf. Accessed 5 Nov. 2017.

Klesse, Christian. "Racialising the Politics of Transgression: Body Modification in Queer Culture." Social Semiotics, vol. 17, no. 3, 2007, pp. 275-92. Taylor \& Francis Online, DOI: $10.1080 / 10350330701448561$.

Loste, Bárbara. "An Interview with Artist Rubén Trejo." Latino Studies, vol. 1, no. 3, 2003, pp. 452-57. ProQuest, DOI: 10.1057/palgrave.Ist.8600050.

Mäkelä, Maarit. "Knowing Through Making: The Role of the Artefact in Practice-Led Research." Knowledge, Technology \& Policy, vol. 20, no. 3, 2007, pp. 157-63. Springer, DOI: 10.1007/s12130-007-9028-2.

Malins, Peta. "An Ethico-Aesthetics of Heroin Chic: Art, Cliché and Capitalism." Deleuze the the Body. Eds. Laura Guillaume and Joe Hughes. Edinburgh UP, 2011, pp. 165-87.

Mulvey, Laura. "A Phantasmagoria of the Female Body: The Work of Cindy Sherman." New Left Review, no. 188, 1991, pp. 137-50. newleftrevieworg.ezproxy.lib.ryerson.ca///188/laura-mulvey-a-phantasmagoria-of-the-femalebody-the-work-of-cindy-sherman. Accessed 23 Oct. 2016. 
Poletti, Anna. "Periperformative Life Narrative: Queer Collages." GLG: A Journal of Lesbian and Gay Studies, vol. 22, no. 3, 2016, pp. 359-79. Project Muse, DOI: 10.1215/10642684-3479414.

Raphael, Mitchel. "Relying on the Cleanliness of Strangers: Upset by His Mother's Refusal to Buy Him Superhero Underwear as a Child, Will Munro has Built an Art Form Out of Recycled Y-Fronts: National Edition." National Post, 6 July 1999, B9. ProQuest, ezproxy.lib.ryerson.ca/login?url=http://search.proquest.com/docview/329544891?a ccountid=13631. Accessed 23 Oct. 2016.

Saline Infusion and You. www.salineinfusion.info. Accessed 23 Oct. 2016.

Sedgwick, Eve K. "Queer and Now." The Routledge Queer Studies Reader. Eds. Donald E. Hall and Annamarie Jagose. Routledge, 2013, pp 3-17.

Seely, Stephen D. "How do You Dress a Body without Organs?: Affective Fashion and Nonhuman Becoming." WSQ: Women's Studies Quarterly, vol. 41, no. 1, 2013, pp 247-65. Project Muse, DOI: 10.1353/wsq.2013.0069.

Small, Zachary. "The Quintessentially Queer Art of Collage." Hyperallergic, https://hyperallergic.com/341239/the-quintessentially-queer-art-ofcollage/?utm_content=buffer4d7c1\&utm_medium=social\&utm_source=twitter.com \&utm_campaign=buffer. Accessed 4 Nov. 2017.

Smelik, Anneke. "Gilles Deleuze: Bodies-without-Organs in the Folds of Fashion." Thinking Through Fashion: A Guide to Key Theorists. Eds. Agnès Rocamora and Anneke Smelik. I.B. Tauris, 2016, pp. 165-83. 
Summers, Jeffrey A. "A Complication of an Unusual Sexual Practice." Southern Medical Journal, vol. 96, no. 7, 2003, pp. 716-17. Academic OneFile, DOI: 10.1097/01.SMJ.0000078368.00806.A7.

The Exorcist. Directed by Williams Friedkin, performances by Ellen Burstyn, Max von Sydow, and Linda Blair, Warner Bros., 1973.

The Human Centipede (First Sequence). Directed by Tom Six, performances by Dieter Laser, Ashley C. Williams, and Ashlynn Yennie, Six Entertainment, 2009.

The Silence of the Lambs. Directed by Jonathan Demme, performances by Jodi Foster and Anthony Hopkins, Orion Pictures, 1991.

Vänskä, Annamari. "A Heroic Man and a Beautiful Woman. Teemu Mäki, Orlan and the Ambivalence of the Grotesque Body." NORA - Nordic Journal of Feminist and Gender Research, vol. 10, no. 3, 2002, pp. 154-67. Scholars Portal, DOI: 10.1080/080387402321012180.

Vaughan, Kathleen. "Pieced Together: Collage as an Artist's Method for Interdisciplinary Research." International Journal of Qualitative Methods, vol 4, no. 1, 2005, pp. 27-52. Sage, DOI: 10.1177/160940690500400103.

Vaughan, R. M. "Spotlight: Sinbad in the Rented World." Canadian Art, 15 Sept. 2004. canadianart.ca/features/sinbad-in-the-rented-world-agyu/. Accessed 23 Oct. 2016.

White, Michele. "Listing eBay Masculinity: Erotic Exchanges and Regulation in 'Gay' and ‘Gay Interest’ Underwear and Swimwear Auctions." Journal of Gender Studies, vol. 19, no. 1, 2010, pp. 43-58. Scholars Portal, DOI: 10.1080/09589230903525437. 
Wood. Mitchell J. "The Gay Male Gaze: Body Image Disturbance and Gender Oppression Among Gay Men." Journal of Gay \& Lesbian Social Services, vol. 17, no. 2, 2004, pp. 43-62. Scholars Portal, DOI: 10.1300/J041v17n02_03. 